\title{
Medulloblastoma: Clinical and biologic aspects
}

\author{
Roger J. Packer, ${ }^{1}$ Philip Cogen, Gilbert Vezina, and Lucy B. Rorke \\ Departments of Neurology [R.J.P.], Pediatrics [R.J.P.], Neurosurgery [P.C.], and Diagnostic Imaging [G.V.], \\ Children's National Medical Center, Washington, DC 20010; Departments of Neurology [R.J.P.], Pediatrics \\ [R.J.P.], Neurosurgery [P.C.], and Radiology [G.V.], The George Washington University Hospital, Washington, \\ DC 20010; and the Department of Pathology, Children's Hospital of Philadelphia, University of Pennsylvania, \\ Philadelphia, PA 19104 [L.B.R.]
}

\begin{abstract}
Medulloblastoma is the most common childhood primary CNS tumor, and treatment approaches have evolved over the past three decades. The biologic underpinnings of medulloblastoma are not fully characterized, but recent work has identified new, important directions for research. Stratification of patients with medulloblastoma into risk groups is the backbone of most ongoing therapeutic studies. Patients are usually characterized as being either average risk or poor risk, although an intermediate risk group may exist. Standard treatment for older children with medulloblastoma consists of radiation and, for most, chemotherapy. Children with nondisseminated disease at the time of diagnosis have been reported to have as high as an $80 \%$ five-year disease-free survival rate after treatment with reduced dose $(2340$
\end{abstract}

Received 15 December 1998, accepted 29 March 1999.

${ }^{1}$ Address correspondence and reprint requests to Roger J. Packer, MD, Department of Neurology, Children's National Medical Center, 111 Michigan Avenue, NW, Washington, DC 20010.

${ }^{2}$ Abbreviations used are as follows: CCG, Children's Cancer Group; CCNU, 1-(2-chloroethyl)-3-cyclohexyl-1-nitrosourea; CSF, cerebrospinal fluid; GFAP, glial fibrillary acidic protein; $\mathrm{H} \& \mathrm{E}$, hematoxylin and eosin; NFP, neurofilament protein; NOS, not otherwise specified; PNETs, primitive neuroectodermal tumors.

${ }^{3}$ Zimmerman, R.A., Bilaniuk, L.T., Sutton, L.N., and Phillips, P. (1993) Systematic evaluation of spinal PNET dissemination by gadolinium enhanced MR. Presented at the 5th International Symposium on Pediatric Neuro-Oncology.

${ }^{4}$ Israel, M., (1999) Personal communication.

${ }^{5}$ Kuhl, J., (1999) Personal communication.

${ }^{6}$ Allen, J., (1999) Personal communication.
cGy) craniospinal irradiation, local boost radiation therapy (5500 cGy), and chemotherapy, given during and after radiation therapy. Preradiation chemotherapy has yet to be shown to be of benefit for children with medulloblastoma. Children with disseminated disease are a highly problematic subgroup of patients to treat. A variety of new approaches are being studied, most of which are intensifying chemotherapy either prior to or after radiation. Long-term survivors of medulloblastoma are at significant risk for permanent endocrinologic, cognitive, and psychological sequelae. Infants and very young children with medulloblastoma remain a difficult therapeutic challenge because they have the most virulent form of the disease and are at highest risk for treatment-related sequelae. Neuro-Oncology 1, 232-250, 1999 (Posted to Neuro-Oncology [serial online], Doc. 98-29, June 15, 1999. URL <neuro-oncology.mc.duke.edu>)

$\mathrm{M}$ edulloblastoma is the most common malignant primary nervous system tumor occurring in childhood, and of all childhood primary brain tumors, the one evoking the most controversy. By definition, medulloblastomas arise in the posterior fossa. Some authors have suggested that all tumors histologically indistinguishable from medulloblastomas be classified as PNETs $^{2}$ and then subdivided on the basis of location (Rorke et al., 1983). Others have argued that the medulloblastoma is a biologically unique tumor, and the most recent World Health Organization classification of tumors has designated medulloblastoma as a distinct subset of embryonal tumor, separating it from other tumors including ependymoblastomas, PNETs, and pineal parenchymal tumors, including pineoblastomas (Kleihues et al., 1993).

Treatment approaches for medulloblastomas have evolved slowly over the past 30 years. Diagnosis and 


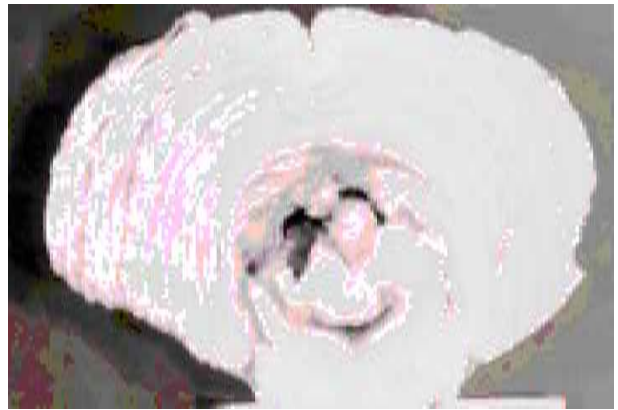

Fig. 1. Transverse section of cerebellum and pons showing multinodular primitive neuroectodermal tumor within vermis with projection into ventricle.

evaluation for extent of disease have been greatly simplified by the routine use of MRI. Studies performed in the 1970s, first with myelography and later with MRI, demonstrated that medulloblastomas frequently are not localized at the time of diagnosis (Allen and Epstein, 1982; Deutsch and Reigel, 1981) and reemphasized the need for treatment of the entire craniospinal axis at the time of initial treatment. Determination of extent of disease at the time of diagnosis has been the backbone of staging studies for children with medulloblastomas, and patient stratification is an integral component of most management schema (Evans et al., 1990).

With the possible exception of germ cell tumors, medulloblastomas are the childhood primary CNS tumor most responsive to radiation and chemotherapy. Treatment with radiation therapy alone results in disease control in over one-half of all children with medulloblastomas, and the addition of chemotherapy may result in disease control in $>80 \%$ of certain subsets of patients with such tumors, especially in those patients with localized disease at the time of diagnosis (Evans et al., 1990; Packer et al., 1994). However, it is now well recognized that many children who are long-term survivors will have significant permanent sequelae. This is especially true for young children diagnosed with medulloblastoma who are at highest risk for severe, often progressive, neurocognitive dysfunction (Packer et al., 1989). Management approaches must deal with the double-edged sword of disease control and the likelihood that therapy will cause life-impairing deficits.

\section{Epidemiology}

Medulloblastomas comprise approximately $20 \%$ of all primary CNS tumors occurring in patients $<18$ years of age (Packer et al., 1990). The tumor may occur in older patients, but comprises probably no more than $1 \%$ of all adult primary CNS tumors (Bloom and Bessel, 1990). In adults, most medulloblastomas will occur in patients $<40$ years of age, and the tumor rarely is initially diagnosed beyond the fifth decade of life. In childhood, medulloblastomas have been reported to have a bimodal distribution, peaking at three to four years of age, and then again between eight and nine years.
The etiologies of medulloblastoma are unknown for most patients. Despite some preliminary observations to the contrary, epidemiological studies have not disclosed a clear-cut link between parental occupation or exposures and the development of medulloblastomas. Parental pesticide use and parental occupational contact with hydrocarbons and metals have been associated with higher incidence of childhood brain tumors in some but not in all studies (Colt and Blair, 1998; Zahm and Ward, 1998). Similarly, there is conflicting evidence between exposure to $N$-nitroso compounds and the development of medulloblastomas (Bunin et al., 1993). In experimental animals, phenotypically similar tumors have been induced by the perinatal intracerebral injection of the JC virus and in rats by retrovirus-mediated transvection of fetal brain cells with the large T antigen of the SV40 (Eibl et al., 1994). A clear-cut relationship between viral exposure and the development of medulloblastoma in humans, however, has never been demonstrated.

Medulloblastomas rarely have been reported in both monozygous twins and dizygous twins. Several familial cancer syndromes have been recognized in children with medulloblastomas, including TP53 germline mutation syndromes, the nevoid basal cell carcinoma syndrome, Gorlin's syndrome, and Turcot's syndrome.

\section{Pathology}

PNETs most commonly arise in the cerebellar vermis but may be found in cerebrum, pineal, brainstem, or spinal cord (Fig. 1). They tend to be poorly defined pink-tan soft growths that sometimes contain foci of hemorrhage and/or necrosis. Those with a prominent desmoplastic component are more firm; cysts are uncommon. Tumors arising in the pineal body are extraordinarily vascular.

Medulloblastomas display a strong tendency to spread through cerebrospinal pathways and form tumors of variable size along ventricular surfaces, in subarachnoid space, or along nerve roots. They sometimes grow en plaque adjacent to brain or spinal cord (see Fig. 2).

Distant metastases are rare, but when they occur spontaneously, their most likely destination is the bone marrow. Individuals who have ventriculoperitoneal

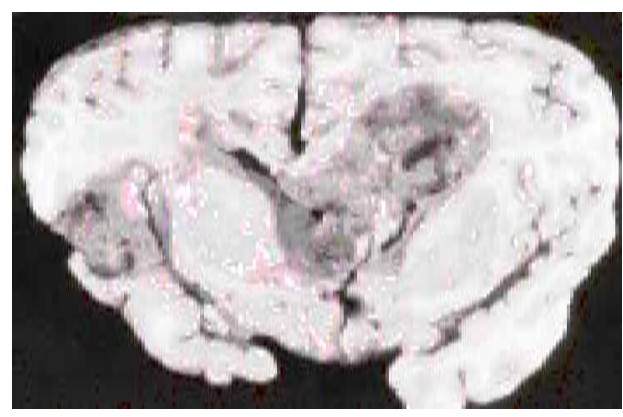

Fig. 2. Coronal section of cerebrum showing multiple metastases from cerebellar primitive neuroectodermal tumor. Note growth along ventricular surface with invasion of brain plus separate cortical metastasis. 


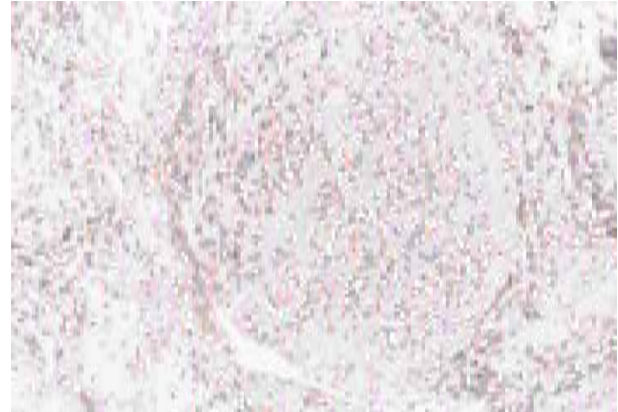

Fig. 3. Tumor cells arranged in "pale island" partially surrounded by delicate connective tissue. $\mathrm{H} \& \mathrm{E}, \times 250$.

shunts are at risk for implantation and growth of tumor cells in the peritoneal cavity.

\section{Microscopic Pathology}

The histologic features of PNETs in the CNS are simultaneously straightforward and complex. They are generally categorized as small blue-cell tumors, a simple description that is acceptable for many of them. At the same time, if a diagnosis of PNET is reserved for only those tumors consisting entirely of a dense population of cells with small, round, deeply basophilic nuclei and little or no surrounding cytoplasm, a significant number of PNETs will not be correctly diagnosed.

Recognition of various histologic subtypes of PNETs led Rorke et al. (1985) to propose a classification system that takes these features into account. However, this scheme does not specifically define the histologic variant called desmoplastic medulloblastoma or other unusual subtypes described below. As the name desmoplastic implies, these tumors harbor a prominent connective tissue component, typically in the form of delicate fibrous strands along which tumor cells are oriented, or around the circumferences of so-called "pale islands"(Fig. 3). Tumor cells in the pale islands have round to oval nuclei with a speckled chromatin pattern and are loosely arranged within a neuropil-type background. This pattern is sometimes confused with another histologic subtype that has been called cerebellar neuroblastoma (Pearl and Takei, 1981; Yagashita et al., 1980). There is inconsistent expression of differentiation antigens in the pale islands, although some tumor cells in this histological subtype typically express NFP.

Delineation of the different diagnostic categories by Rorke et al. (1985) is primarily based upon a combination of routine light microscopic features using H\&E and the pattern of expression of various antigens using immunoperoxidase methods. Ultrastructural studies are currently minimally used for diagnosis.

PNETs, not otherwise specified. These tumors are the prototype small blue-cell tumor mentioned above and consist of an apparently homogeneous population of primitive neuroepithelial cells. These typically are set within a granulofibrillar background, but in a small proportion this is absent (Fig. 4). Extent of mitotic activity and individual

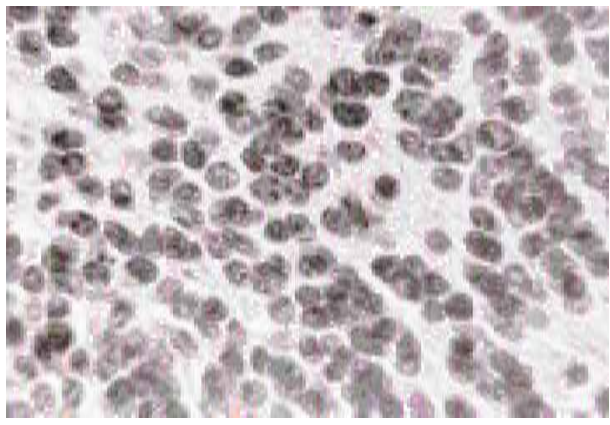

Fig. 4. Primitive neuroectodermal tumor composed of monotonous population of cells with small round nuclei with abundant chromatin and no discernible cytoplasm. $\mathrm{H} \& \mathrm{E}, \times 400$.

cell necrosis is variable; field necrosis may be striking. Vascularity is also variable, but in general is relatively inconspicuous. Some PNETs are composed of cells with larger round to oval nuclei that have a lightly speckled chromatin pattern and sometimes contain a small nucleolus. These cells also tend to have recognizable perikaryal borders and one end may be slightly tapered (see Fig. 5).

About $20 \%$ of PNETs contain Homer Wright rosettes. It has been asserted that the presence of such rosettes is an indicator of neuronal differentiation, but neuronal antigens are inconsistently expressed in them.

Tumors are placed in the category of PNET-NOS when component cells do not contain melanin or express any specific differentiation antigen.

PNETs with neuronal differentiation. These tumors may display the light microscopic features with H\&E described above, but in addition express NFP. Typically, the neoplastic cells that express NFP are not recognizably different (with H\&E) from cells that show no expression. In general, the expression appears to be clonal (see Fig. 6A). Less common is diffuse expression of NFP.

It is mistakenly assumed by some that expression of synaptophysin is indicative of neuronal differentiation. Gould et al. (1990a) have demonstrated that synaptophysin is a neuroendocrine marker similar to bombesin and vasoactive peptide (which are also expressed in

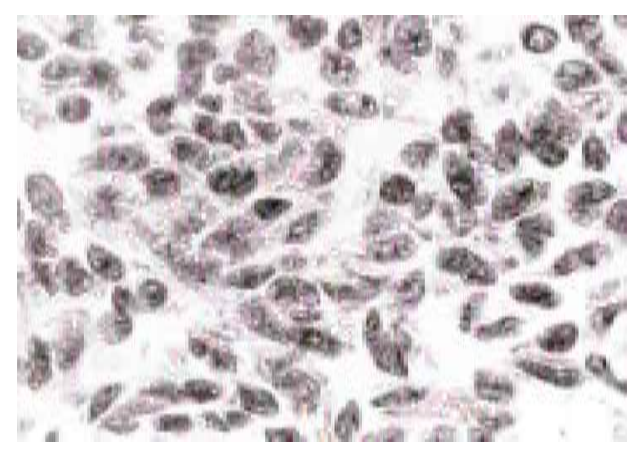

Fig. 5. Primitive neuroectodermal tumor composed of pleomorphic cells with medium-to-large sized nuclei. Note variability in nuclear contour. $\mathrm{H} \& \mathrm{E}, \times 400$. 

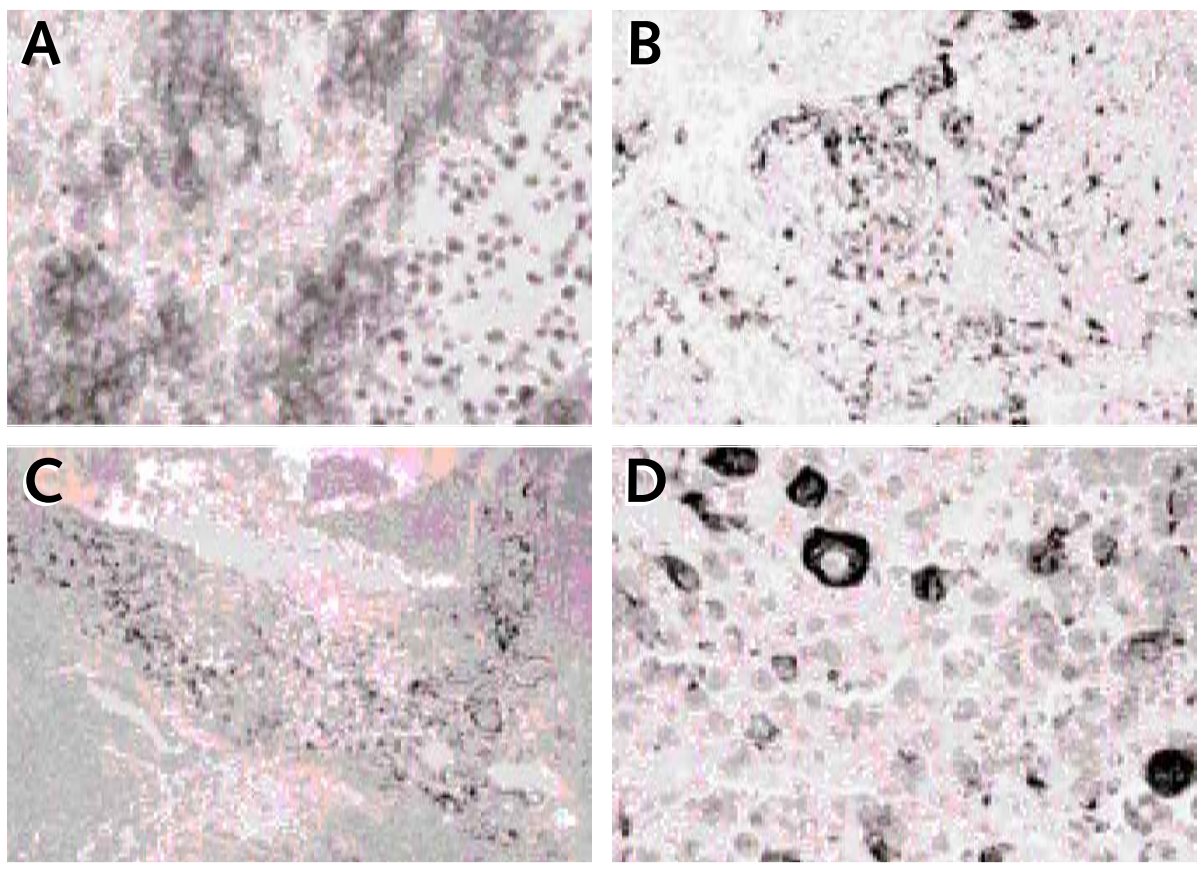

Fig. 6. A. Immunoperoxidase preparation, with antibody for visualizing neurofilament protein, showing clonal nature of neurofilament protein expression. $\times 250$. B. Immunoperoxidase preparation, with antibody for visualizing glial fibrillary acidic protein, showing expression in scattered tumor cells. $\times 100$. C. Section of cerebellar primitive neuroectodermal tumor containing large group of melanocytic cells. H\&E, $X 100$. $D$. Immunoperoxidase preparation, with antibody for visualizing desmin, showing striking expression in scattered large cells resembling neurons. $X 250$.

PNETs), and indeed, that all PNETs express synaptophysin. Thus, its major value is in differentiating PNETs from other small blue-cell tumors in the CNS.

A histologic subtype of PNETs with neuronal differentiation appears in the literature as cerebellar neuroblastoma and has already been mentioned above in the discussion of desmoplastic medulloblastoma. In this subtype of PNETs with neuronal differentiation, however, the linear arrangement of primitive neural cells forms in a neuropil-type matrix and resembles migrating postmitotic neuroblasts along radial glia characteristic of the developing brain (see Fig. 7). These tumors also contain pale islands in which NFP expression may or may not be seen.

A small group of PNETs exhibit obvious terminal differentiation into easily recognized neurons, usually in fields resembling gray matter (Fig. 8). Transitions from the less to the more differentiated regions are clearly visible in H\&Estained preparations. Neurons within the islands of neuropil tend to vary in size; rarely, a binucleated form is seen.

Other markers of neuronal differentiation, such as microtubule associated protein (MAP II) or Class III beta tubulin have also been used to study these tumors (Katsetos et al., 1993; Molenaar et al., 1993).

PNETs with glial differentiation. Diagnostic criteria for placing tumors in this category are sometimes problematic, as there is disagreement regarding interpretation of the stellate astrocytic forms that are sometimes found upon application of the GFAP antibody.

Tumors in this diagnostic niche may be composed of apparently undifferentiated neuroepithelial cells, as described above, or a small proportion may contain fields composed of obviously anaplastic astrocytes (see Fig. 9).

Absent such findings, use of a GFAP antibody assists in recognition of primitive cells that have differentiated along glial lines. There is less of a tendency for clonal expression of GFAP than is the case of tumor cells that express NFP (see Fig. 6B).

The primitive neuroepithelial cells that express either GFAP or NFP typically display a thin halo of brown around the nucleus. However, some tumors contain stellate cells that look like reactive astrocytes and, for the most part, are interpreted as such. On the other hand, stellate forms have been identified in bone marrow and PNETs metastatic to the abdominal cavity, suggesting the possibility that these mature, reactive-appearing astrocytes are actually a manifestation of terminal differentiation (see Fig. 4 in Rorke et al., 1997). This phenomenon would parallel the finding of mature neurons in the PNETs with neuronal differentiation, as described above.

It has been suggested that PNETs may differentiate along oligodendroglial lines, but there is no current support in favor of this allegation. Identification of cells with clear, perinuclear halos resembling the so-called "friedegg" appearance of oligodendroglia within PNETs is most likely a fixation artifact. However, resolution of this issue awaits a reliable marker for neoplastic oligodendrocytes.

PNETs with ependymal differentiation. Rarely, examination of a PNET with H\&E discloses the presence of ependymal canals of variable size amidst the larger population of primitive cells (see Fig. 10). In the past, such tumors have been called ependymoblastomas (Rubinstein, 


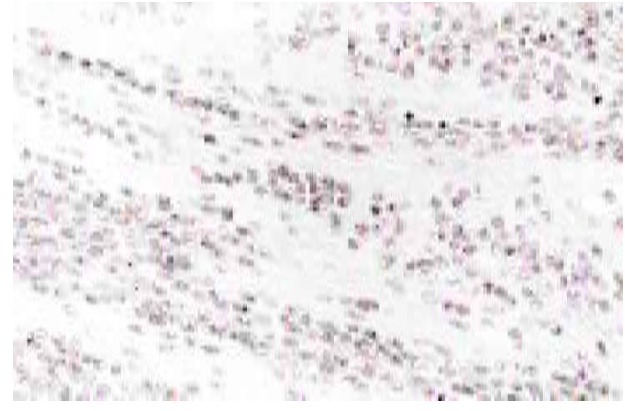

Fig. 7. Rows of primitive neuroepithelium in neuropil-type stroma resembling immature neurons migrating along radial glia. $H \& E, \times 250$.

1970). Their ependymal nature may be confirmed by use of an antibody for GFAP and/or by ultrastructural study.

PNETs with melanocytic differentiation. PNETs with component cells containing melanin are rare, but this diagnosis, too, may be made on examination with an H\&E stain, and confirmed by use of a Fontana stain or with the antibody HMB-45, which recognizes melanin (see Fig. 6C). PNETs containing melanin also tend to express desmin, NFP, and/or GFAP. Those arising in the pineal sometimes express retinal $\mathrm{S}$ antigen as well.

PNETs with muscle differentiation. Tumors of this histological type are rare, and when originally identified were called medullomyoblastoma (Marinesco and Goldstein, 1933). They consist of primitive neuroepithelial cells and a variable amount of striated or smooth muscle, both of which are identifiable with $\mathrm{H} \& \mathrm{E}$ but are most clearly demonstrated by use of antibodies for desmin and smooth muscle actin (Fig. 6D). Actually, PNETs containing muscle fibers typically exhibit expression along multiple pathways, for example, neuronal, glial, and/or melanocytic.

Some PNETs do not contain recognizable muscle fibers, but the apparently undifferentiated neuroepithelial cells may express desmin. Indeed, Gould et al. (1990b) have documented dual or triple expression of desmin with other antigens, such as vimentin, NFP, and/or GFAP.

PNETs with retinal differentiation. A small number of CNS PNETs contain Flexner-Wintersteiner rosettes and fleurettes, most notably those that arise in the pineal body, supporting the established biologic relationship between the pineal and retinal epithelium, which gives rise to retinoblastomas, tumors that bear a striking histological resemblance to PNETs.

Somewhat surprising, however, were the observations of Korf et al. (1990; 1992), who reported relatively frequent expression of retinal antigens in PNETs of the posterior fossa. They used retinal $S$ and rhodopsin, two antigens normally found in retinal epithelium. Naturally, pineal PNETs may also express these two antigens.

CNS PNETs that express retinal antigen also contain cells that express NFP. However, there are no studies to date that have investigated whether there is dual expression of NFP and retinal antigens.

PNETs with multidirectional differentiation. The increasing use of multiple monoclonal antibodies, the application of special techniques for recognition of dual or triple expression in tumor cells, and immunoblot methods have expanded our view of the biological features of PNETs. Molenaar et al. (1989) and Gould et al. (1990b) have documented evidence of expression of multiple antigens, sometimes in different cell populations, but also multidirectional expression in a given cell. Thus, one or more cells may simultaneously express GFAP, NFP, and desmin, for example, or other combinations of antigens. Such behavior by cells comprising PNETs is not rare and raises intriguing questions regarding oncogenesis of this family of tumors.

Other histological subtypes of primitive neuroectodermal tumor. Lipomatous (lipidized) medulloblastoma. It is generally conceded that there are significant differences between the biology and histologic types of CNS tumors in infants and children in contrast to those that occur in adults. This difference is particularly striking when frequency of PNETs in a population of children is compared with that found amongst adults. Specifically, about $20 \%$ of primary CNS tumors in children are PNETs, whereas only about $3 \%$ of CNS tumors in adults fall into this category (Rorke, 1994). Remarkably, one type of PNET has, to date, been found only in adults. This tumor has been called lipomatous (Soylemezoglu et al., 1996) or lipidized (Davis et al., 1993) medulloblastoma. Except for the lipidized cells, these tumors are typical PNETs in that other cells in the tumors may express NFP or synaptophysin.
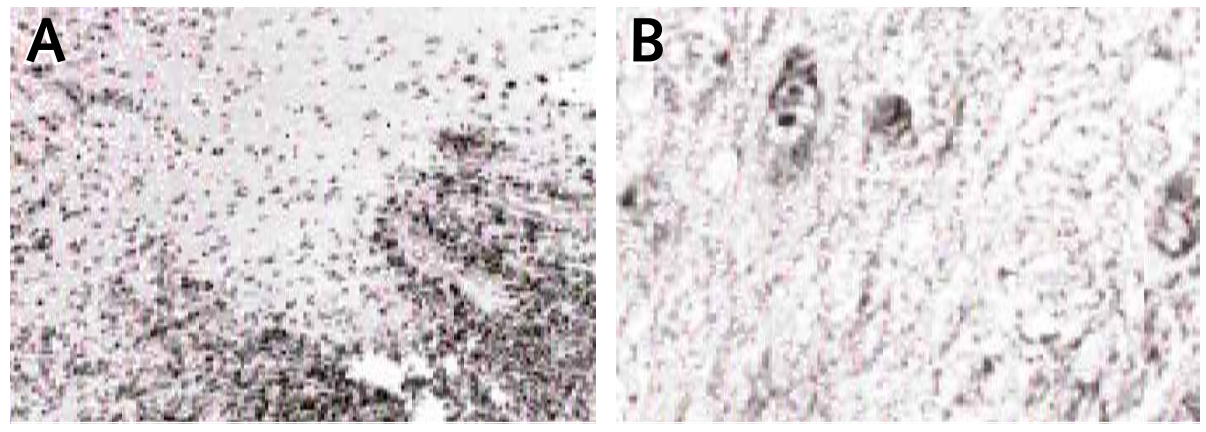

Fig. 8. A. Cerebellar primitive neuroectodermal tumor showing primitive neuroepithelial cells in bottom and right side of the field, and neoplastic neural tissue containing small and large neurons in remainder of the field. H\&E, $\times 100$. B. High magnification photomicrograph of neurons in the same tumor shown in $8 \mathrm{~A}$. $H \& E, \times 250$. 


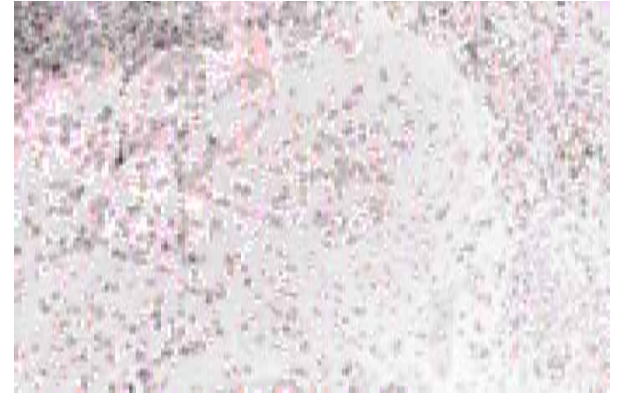

Fig. 9. Nest of anaplastic astrocytes in the midst of primitive neuroepithelial cells. $\mathrm{H} \& \mathrm{E}, \times 250$.

Large-cell medulloblastoma. In 1992, Giangaspero and colleagues reported four patients with cerebellar tumors consisting of unusually large round cells with prominent nucleoli, and whose clinical course evolved and terminated in death relatively rapidly. Comparison of the clinical and pathologic features of these cases suggests the possibility that they actually belong to the diagnostic entity called atypical teratoid/rhabdoid tumor.

The atypical teratoid/rhabdoid tumor was defined as an entity separate from PNETs, the tumor type with which they are most commonly confused, primarily because $60-70 \%$ of atypical teratoid/rhabdoid tumors contain fields indistinguishable from typical PNETs (Rorke et al., 1996). Basically, these are tumors that occur primarily in infants less than two years of age and which exhibit an aggressive clinical course that, in most patients, results in death within a year of diagnosis.

The unique feature of these tumors consists of the rhabdoid cell component in combination with fields of typical PNET with or without epithelial and/or mesenchymal features. The rhabdoid cell is histologically similar to the large cell in the large cell medulloblastomas. It has a perikaryon about equal in size to the round nucleus, which is centrally or more often eccentrically placed and which typically contains a prominent nucleolus (see Fig. 11). Both mitotic activity and necrosis are striking. Vessels may be abundant but they are thinwalled and, in fact, often rupture, causing hemorrhages that may be massive. The epithelial component may be glandular or squamous, and the mesenchymal portions are basically neoplastic fibroblastic elements.

The rhabdoid cells exhibit a unique combination of differentiation antigens including epithelial membrane antigen, vimentin, and smooth muscle antigen, but they may also express NFP, GFAP, and/or keratin. Although rhabdoid cells also resemble the large cells seen in germinomas, markers for germ cell tumors are not expressed in atypical teratoid/rhabdoid tumors.

\section{Biology}

An understanding of the basic biology of medulloblastoma has been hampered by several experimental difficulties. Although the tumor is an aggressive, malignant lesion, primary cell cultures of tumor explants have been difficult to maintain. Several of the long-term commercially available cell lines have recently been shown to have lost the histologic and immunohistochemical characteristics typical of medulloblastoma, and thus results of studies using these lines are suspect. The best success in establishing and maintaining medulloblastoma cell lines has been through the use of tumor tissue transplanted into nude mice. Further, many primary tumor specimens examined by karyotype analysis show marked aneuploidy, with rearranged and unidentifiable chromosomes and fragments. The use of fluorescence in situ hybridization analysis has allowed the identification of these previously unknown chromosomes.

Despite these and other problems with tissue sampling, cell line growth, and identifying key characteristics, much has been learned about the basic genetic and molecular genetic constitution of medulloblastoma. Conventional cytogenetic analysis has revealed loss of genetic material from the short $(\mathrm{p})$ arm of chromosome 17 to be the most common feature of medulloblastoma, most often identified as an isochromosome 17q (loss of the entire $\mathrm{p} \mathrm{arm}$ ) (Biegel et al., 1989). Loss of 17p DNA has been identified in $30-50 \%$ of tumor specimens examined by standard cytogenetic analysis: In one half of these cases, it is the only abnormality identified. Other sites of DNA loss have been identified by cytogenetic analyses supplemented by molecular genetic techniques employing restriction fragment length polymorphism and polymerase chain reaction-based probes. Common sites of loss have been detected on chromosome arms 5q, 10q, and 16q, as well as chromosomes 6, 9, 11, and 22 (Thomas et al., 1991). Recently, comparative genomic hybridization has been used to examine medulloblastoma specimens. This is a technique that uses fluorescent-labeled DNA obtained from both normal and tumor cells hybridized to a normal metaphase spread to detect DNA loss and amplification by examining the resulting color patterns. Loss of DNA has been identified at sites previously detected by other means as well as novel locations including $8 \mathrm{p}$, and new amplification sites have also been detected that include $5 \mathrm{p}$ and 11q (Reardon et al., 1997). As with previous cytogenetic studies, the results of comparative genomic hybridization for medulloblastomas differ in the various reported series, likely due to both the differing molecular constitutions of the various specimens examined and the technical variability between investigators.

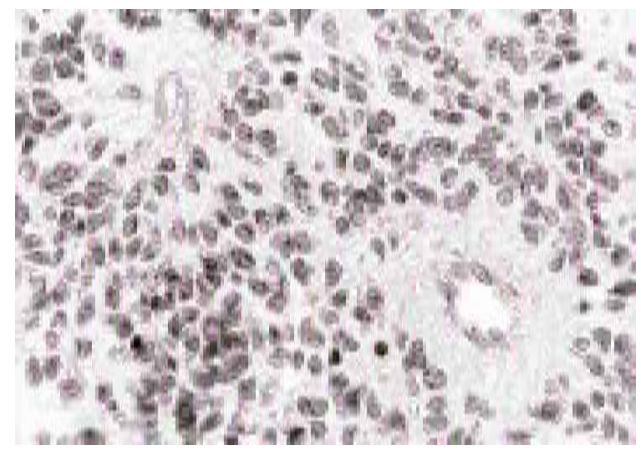

Fig. 10. Pseudorosettes in cerebellar primitive neuroectodermal tumor displaying ependymal differentiation. H\&E, ×250. 
Much of the previous research on loss of DNA sequences in medulloblastoma has focused on those located on chromosome arm 17p. Consistent deletion of $17 \mathrm{p}$ markers has been shown in $35-40 \%$ of tumor specimens examined to date, with a pattern of loss of the entire short arm or of those markers clustered at the distal part of the arm at 17p13.3 (McDonald et al., 1994). Initial interest was sparked when the now ubiquitous TP53 tumor suppressor gene was identified on $17 \mathrm{p} 13.1$. However, several studies of medulloblastoma tumor specimens have shown loss and mutation of the TP53 tumor suppressor are uncommon in this tumor, a surprising observation, given the aggressive malignancy of this lesion (Cogen et al., 1992). Recently, hypermethylation of DNA on $17 p$ associated with the HIC1 gene has been frequently documented in medulloblastoma. As HIC1 acts through TP53, this raises the possibility of a mechanistic interaction for this tumor suppressor in medulloblastoma not previously identified. Although loss of 17p DNA has been shown to be of prognostic significance in average risk medulloblastoma in at least two series, other investigators have not consistently obtained these results and additional studies need to be pursued (Cogen and McDonald, 1996).

Recently, attention has focused on loss and mutation of tumor suppressor genes associated with familial syndromes that predispose to medulloblastoma. The basal cell nevus syndrome consists of multiple skin cancers unassociated with sunlight exposure, rib and jaw anomalies, and a predisposition to medulloblastoma. The responsible gene (NBCCS, nevoid basal cell carcinoma gene) has been cloned and lies on chromosome $9 \mathrm{q}$, a site of frequent loss of heterozygosity in medulloblastoma tumor specimens. The human gene is a homolog of the drosophila gene patched, and mutations of this gene have been identified in familial basal cell carcinomas and a subset of medulloblastomas, those of the pathologic desmoplastic type (Xie et al., 1997). Turcot's syndrome, consisting of a familial predisposition to colonic polyps and colon cancer, has been shown to be associated with mutations of the APC (adenomatosis polyposis coli) gene located on chromosome 5 . Despite the association of medulloblastoma with Turcot's syndrome, APC mutations have not been identified to date in medulloblastoma tumor specimens.

A role for the neurotrophin receptor TRKC (tyrosine kinase) has also been postulated for medulloblastoma. Previously, studies of the neurotrophin receptor genes in neuroblastoma showed an association between expression of TRKA and TRKC in tumor specimens with a favorable prognosis, and TRKB expression was associated with a poor outcome (Nakagawara et al., 1993). $T R K C$ expression has also been shown to correlate strongly with favorable prognosis in medulloblastoma. Studies on these and other genes should lead to a better understanding of the biology of medulloblastoma and lead to better prognostic and therapeutic tools.

\section{Presentation and Diagnosis}

Children with medulloblastoma classically present with signs and symptoms of obstruction of CSF flow and cerebellar dysfunction. Papilledema and morning headache,

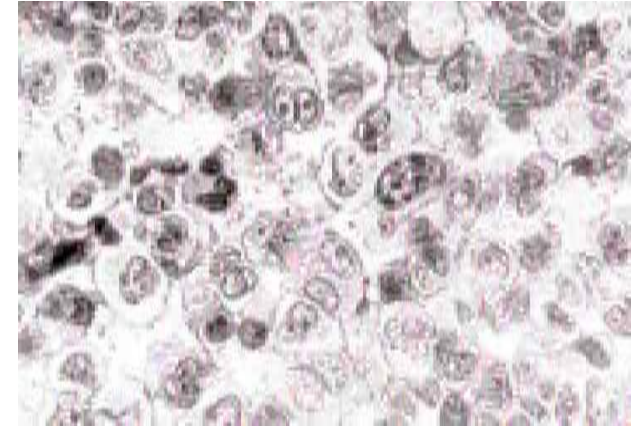

Fig. 11. Field of classical rhabdoid cells showing large size, distinct cell borders, and single or multiple nuclei with prominent nucleoli. $H \& E, \times 400$.

often associated with vomiting and lethargy, are present in over three-fourths of patients at the time of diagnosis. Symptoms are usually present for less than three months before diagnosis, although early in the course of illness, the symptoms may be subtle and intermittent. As the tumor increases in size, there is usually progressive truncal ataxia. Less frequently, the tumor infiltrates the brainstem, causing cranial nerve dysfunctions. Abducens palsy tends to occur relatively early in the disease, more frequently secondary to increased intracranial pressure rather than brainstem involvement. The development of a stiff neck or head tilt usually suggests tonsilar involvement by the medulloblastoma or signs of impending herniation. Less frequently, head tilt is due to a fourth nerve palsy.

Infants with medulloblastoma present less characteristically. Initial symptoms and signs include intermittent vomiting, macrocephaly, and nonspecific signs of ventricular dilitation such as inability to elevate the eyes, the socalled "sun-setting sign."

Although a significant number of children with medulloblastoma have disseminated disease at the time of diagnosis, few will be symptomatic at time of initial presentation.

\section{Neuroradiographic Diagnosis}

Most children with medulloblastoma will be diagnosed by either CT or MRI. On CT, medulloblastomas are usually relatively well-defined homogeneous midline lesions and are either isodense or hyperdense compared with the cerebellar cortex (Zimmerman et al., 1978) (see Fig. 12). In older children, medulloblastomas often lateralize toward the cerebellar hemispheres and the cerebellopontine angles. Multicentric tumors are occasionally seen (see Fig. 13). Approximately 10 to $20 \%$ of patients will have calcification on the noncontrast CT; cystic or necrotic areas are somewhat more frequent (Chambers et al., 1981; Sandhu et al., 1987). After contrast enhancement, the majority of tumors will show homogeneous enhancement, although a significant proportion will have more heterogeneous enhancement and approximately 5 to $10 \%$ will have nonenhancing tumors.

On MRI, the tumor usually presents as a midline inferior vermian lesion filling the fourth ventricle and, at 

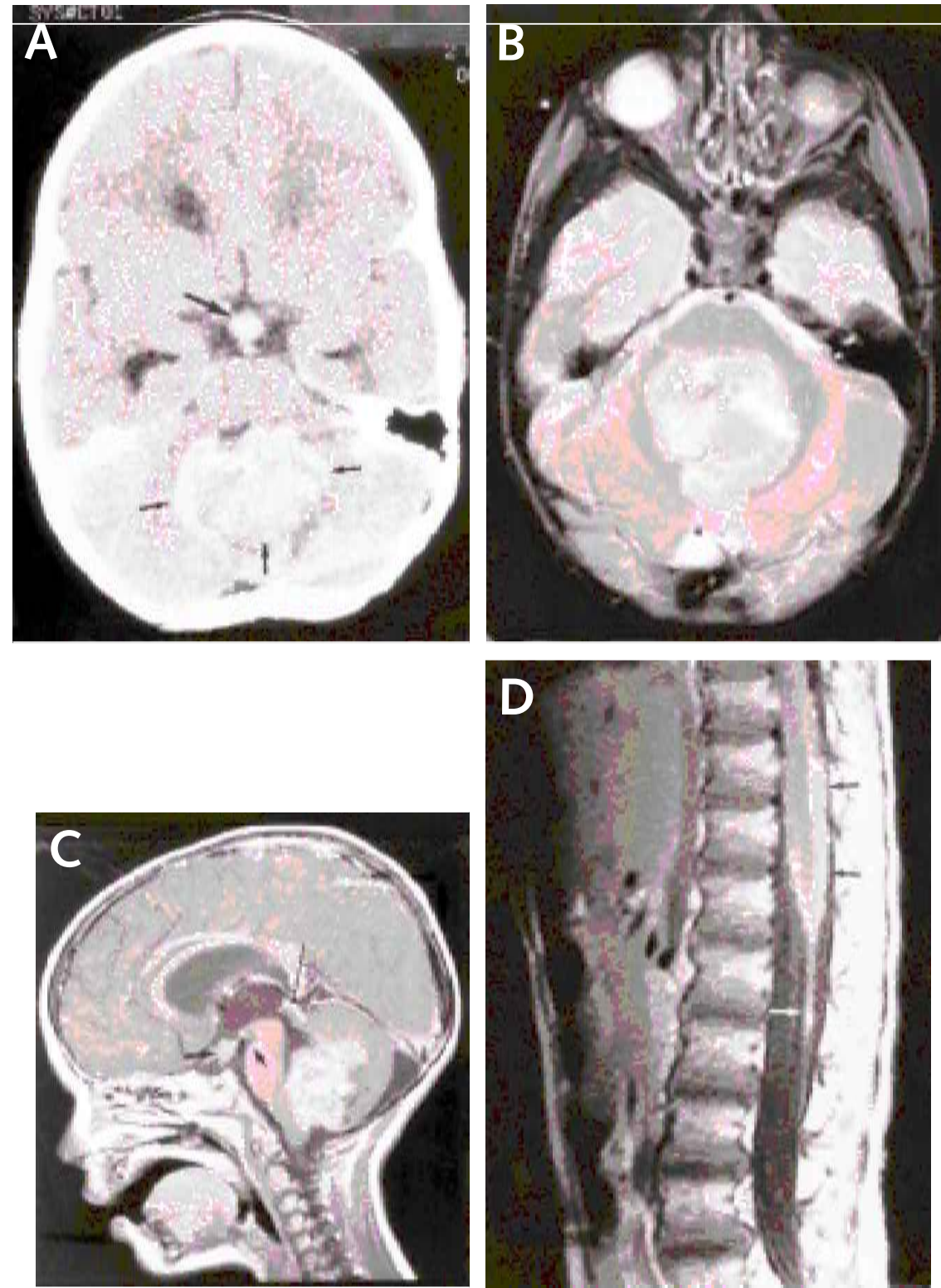

Fig. 12. Typical medulloblastoma in a 3-year-old male. (A) Axial noncontrast CT, (B) axial T2-weighted, and (C) sagittal postcontrast T1weighted images of the brain reveal a hyperdense mass (arrows, A) with a third ventricle metastatic deposit (long arrow, A). Mixed iso- and hyperintense T2 signal is seen (B), as is diffuse, intense enhancement (C). Leptomeningeal involvement of the dorsal tectum (long arrow, C), the infundibular recess of the third ventricle (medium arrow, $\mathrm{C}$ ), and the surface of the pons (short arrows, C) are evident. D. Sagittal enhanced T1weighted image of the lumbar spine reveals diffuse coating of the spinal cord and the filum terminale by enhancing tumor (arrows).

times, extending into the ventricular foramina (Zimmerman et al., 1992). Medulloblastomas are usually low-tointermediate signal on short time to relaxation/time to echo (TR/TE) images and isointense or slightly hyperintense on long TR/TE images (Vezina and Packer, 1994) (see Fig. 12). Most of the tumor is usually homogeneous, but there may be cystic or necrotic foci. Vascular flow voids may also occur. As is the case in CT, homogeneous enhancement is usual, but the lesions may not enhance on MRI (see Fig. 13).

Because of the significant incidence of dissemination at the time of diagnosis, neuroimaging of the entire neuraxis is required prior to the initiation of treatment. In the past, myelography or CT-myelography was utilized to evaluate the neuraxis after surgery. However, MRI is more sensitive than myelography, and it has essentially supplanted it as the neuroimaging technique of choice. ${ }^{3}$ Imaging of the spine after surgery can be difficult due to postoperative blood or other changes. For this reason, most major centers are attempting to image the entire neuroaxis prior to surgery. Disseminated tumors are usually best visualized in the subarachnoid space of the brain or the spinal canal on contrast-enhanced T1-weighted images (see Fig. 14). Gadolinium-enhanced T1-weighted images are more sensitive in depicting subarachnoid spread than contrast-enhanced CT or intrathecal-enhanced 
myelography followed by CT (Rorke et al., 1997). A diagnosis of dissemination may be difficult in nonenhancing tumors (see Fig. 13).

\section{Stratification}

A major component of the management of medulloblastomas is stratification of patients into risk groups to guide therapy (see Table 1). Two studies, one performed by the CCG and the other by the International Society of Pediatric Oncology in the late 1970s and early 1980s, demonstrated that an intraoperative staging system, coupled with evaluation for extent of disease at the time of diagnosis (the Chang staging system), could be used to broadly stratify patients into two risk groups (Evans et al., 1990; Tait et al., 1990). Children with larger tumors, tumors that invaded the brainstem, and/or disseminated lesions carried a poorer prognosis than those patients with smaller tumors that were localized. In addition, younger children in these studies had a poorer prognosis than older patients. The intraoperative staging system was a $\mathrm{T}_{1}-\mathrm{T}_{4}$ staging system based predominantly on the determination of the size and location of the tumor by the surgeon at the time of operation and estimates of the degree of hydrocephalus. Extent of dissemination was determined by intraoperative observation, CSF cytological examination, and postoperative myelography. Patients without metastatic disease are designated as $\mathrm{M}_{0}$; those with positive CSF cytology without evidence of gross disease on myelography are $\mathrm{M}_{1}$ patients; gross nodular seeding along the cerebellum, cerebral subarachnoid space, or into the ventricles are considered $\mathrm{M}_{2}$ patients; those with gross nodular seeding along the spinal subarachnoid space are $\mathrm{M}_{3}$ patients; and those with extraneural metastases are $\mathrm{M}_{4}$ patients.

This staging system for children with medulloblastoma has been altered over time. The T-stage system has essentially been replaced by determination of extent of surgical resection, as it is accepted that the amount of residual tumor after resection is a more important predictive factor than the initial size of the tumor. Determination of the amount of residual disease is based on both the postoperative imaging studies and the surgeon's impression at the end of surgery. Brainstem involvement at the time of diagnosis was found to be a factor predictive of a poorer outcome in earlier series of patients treated with radiation therapy alone (Evans et al., 1990; Tait et al., 1990). However, more recent studies have not been able to demonstrate the independent predictive significance of brainstem involvement (Packer et al., 1994; Zeltzer et al., 1995). The degree of tumor resection has been found to be an independent predictor of outcome only in patients with localized disease at the time of diagnosis (Zeltzer et al., 1995). Patients with large amounts of residual tumor, especially those who are biopsied only, have a poorer prognosis than patients with less residual disease.

Myelography has essentially been supplanted by MRI of the entire neuraxis. Both myelography and MRI can be difficult to evaluate in the postoperative period due to postoperative blood and blood clots. For this reason, spinal MRI is now recommended prior to surgery. The prognostic significance of dissemination has been primarily determined by studies that had used myelography, and these results have been extrapolated to conclude that MRI results can be used to predict outcome. Although this is likely true, MR-based spinal imaging is more sensitive than myelography, and the significance of minimal subarachnoid disease seen on MRI, which would not have been seen on myelography, has never been documented by prospective randomized studies.

Extraneural tumor spread at diagnosis is infrequent and occurs primarily in infants and young children. Most prospective studies are not requiring assessments of bone marrow or skeletal studies at the time of diagnosis, with the possible exception of studies in infants.

At the present time, children with medulloblastoma with $>1.5 \mathrm{~cm}^{2}$ of residual disease and/or any evidence of

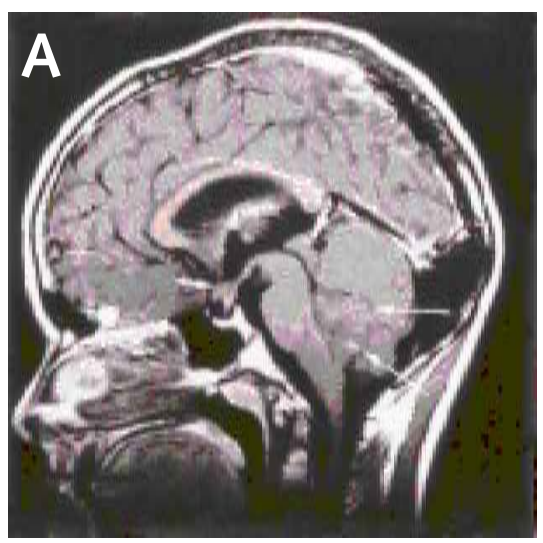

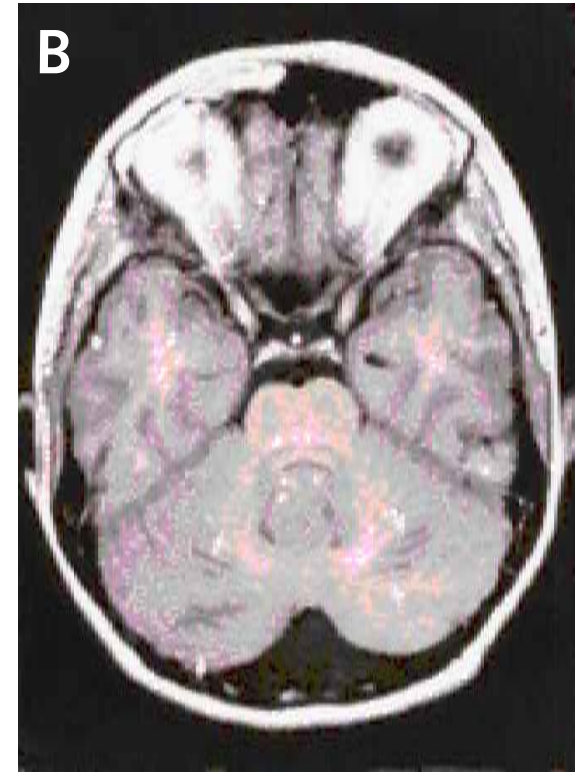

Fig. 13. Nonenhancing disseminated medulloblastoma in an 11-year-old boy. (A) Post contrast sagittal and (B) axial T1 images reveal tumor filling the fourth ventricle (long arrows, A). A nonenhancing metastasis is identified in the inferior recess of the third ventricle (short arrow, A). Nonenhancing deposits cause enlargement of multiple cerebellar folia (confirmed at surgery) (arrows, B). 


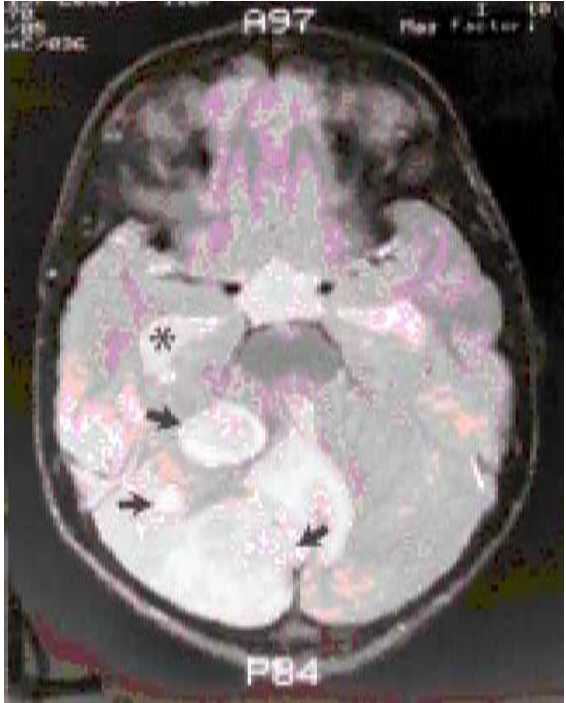

Fig. 14. Multicentric medulloblastoma in a 5-year-old male. Axial T2-weighted image reveals multiple tumor nodules (arrows) within the right cerebellar hemisphere. The fourth ventricle is compressed with resultant hydrocephalus (enlarged right temporal horn marked with asterisk).

dissemination are considered to high- or poor risk patients (see Table 1). Those children with localized disease who have $<1.5 \mathrm{~cm}^{2}$ of residual tumor after surgery are considered to be average risk patients. An intermediate risk group of children probably exists, but has been poorly characterized (see Table 1). Factors that may help define this intermediate risk group of children, but which have not yet been shown to be of independent prognostic value, include brainstem involvement at the time of diagnosis, subtotal resections, and positive CSF cytology for free-floating tumor cells without evidence of bulk disease outside the posterior fossa (Zelter et al., 1995). Treatment affects the value of these predictive factors. In series that have treated children with radiation supplemented with chemotherapy, brainstem involvement and extent of resection (excluding patients who are biopsied alone) were no longer found to be statistically significant predictive factors (Packer et al., 1994) Although age is correlated with outcome, with younger children faring less well than older children, it is difficult to fully separate the impact of treatment from age, as many children less than three years of age have been treated with initial chemotherapy in attempts to avoid radiation therapy. In addition, tumor location is an important prognostic factor for children with PNETs that arise outside the posterior fossa; patients with cerebral PNETs and pineoblastomas have a poorer outcome than patients with medulloblastomas (Zelter et al., 1995).

Other factors have been linked to prognosis for children with medulloblastoma but have not been routinely integrated into staging studies. A significant proportion of medulloblastomas will show light microscopy and immunohistochemical evidence of differentiation along identifiable cellular lines (Rorke et al., 1983). Light microscopy evidence of differentiation has been shown by some to be predictive of a poorer outcome (Packer et al., 1984). Similarly, immunohistochemical evidence of glial differentiation has been linked in one study with poorer outcome (Janss et al., 1996). DNA ploidy studies and mitotic index evaluations have been evaluated in patients with medulloblastomas, but no clear-cut relationships have been found (Gajjar et al., 1993; Zerbini et al., 1993). Genomic alterations have been noted in patients with medulloblastomas, and the presence of an isochromosome $17 \mathrm{q}$ was found by one group of investigators to predict poorer outcome (Cogen et al., 1996). In this series, however, most of the patients were treated with radiation therapy alone, and similar findings have not been documented in series evaluating patients treated with both radiation and chemotherapy. Loss of heterozygosity of chromosome 17 has been demonstrated frequently in medulloblastomas and has been associated, at least in one study, with a higher likelihood of metastatic disease. However, the prognosis of patients with medulloblastomas and loss of heterozygosity $17 \mathrm{q}$ was worse only in children when associated with amplification of c-myc (Scheurlen et al., 1998).

Neurotrophins and neurotrophin-receptor expression have also been studied in patients with medulloblastomas, and a high expression of both TRKC and neurotrophin-3 correlated with favorable outcome in children with medulloblastomas (Segal et al., 1994). However, this has not been demonstrated in a prospective randomized trial. Similarly, the degree of apoptosis, as determined by assays on paraffin sections, was demonstrated by one group to be predictive of outcome, as children with the highest rate of apoptosis had a significantly better survival rate than those with lower rates of apoptosis. ${ }^{4}$ It is unclear whether these biologic factors will, in time, supplement or replace clinical parameters of risk, such as extent of dissemination or extent of surgical resection.

\section{Surgery for Medulloblastoma}

The role of the surgeon in the treatment of medulloblastoma is resection of as much of the primary mass as is possible, guided by the anatomy of the lesion. Factors that preclude a complete resection include brainstem invasion, generally of the floor of the fourth ventricle, adjacent leptomeningeal spread with coating of the subarachnoid spaces, and significant supratentorial extension of the primary posterior fossa mass. In most medulloblastomas, the tumor mass is usually located in the midline of the posterior fossa, either within the fourth ventricle or the cerebellar vermis. However, the desmoplastic variant in particular may be seen adjacent to the lateral part of the cerebellar hemisphere. Most children are operated upon in the prone position (face down) to avoid the complications of the so-called "sitting position." Access to the tumor is gained through a suboccipital craniectomy or craniotomy, and midline tumors are accessed through a partial resection of the cerebellar vermis, with identification and protection of the fourth ventricular floor with a cottonoid pledget. Intraoperative magnification by the microscope is critical to visualizing the tumor and its anatomic relationships to surrounding structures, both to assess the ability to perform a total 
Table 1. Risk groups of childhood medulloblastoma

\begin{tabular}{llll} 
Factors & Average risk & ? Intermediate risk & Poor risk \\
\hline Extent of disease & $\begin{array}{l}\text { Posterior-fossa, } \\
\text { not invading brainstem }\end{array}$ & $\begin{array}{l}\text { Tumor cells/clumps in cerebrospinal } \\
\text { fluid; ? brainstem involvement }\end{array}$ & $\begin{array}{l}\text { Disseminated with intracranial or } \\
\text { spinal disease; extraneural disease }\end{array}$ \\
Extent of resection & Total; near total; ? $<1.5 \mathrm{~cm}^{2}$ residual & ? Subtotal; ? $>1.5 \mathrm{~cm}^{2}$ residual & Biopsy only; minimal resection \\
Age & 7 years or greater; ? 3 years or greater & $?$ & 3 years or younger \\
Histologic & Undifferentiated & ? Differentiated & ? Differentiated; rhabdoid \\
& & & elements; ependymoblastomas \\
Biologic & ? Diploid; high expression TRKC/ & ? Aneuploid; ? isochromosome & ? Aneuploid; ? LOH 17q plus \\
& neurotrophin 3; ? high apoptosic index & 17q; LOH 17q; ? high mitotic & C-myc amplification; low \\
& & index; low apoptotic index & apoptotic index \\
\hline
\end{tabular}

$\mathrm{LOH}$, loss of heterozygosity; ?, questionable significance.

resection safely and to avoid damage to adjacent neural tissue (Cogen and Donahue, 1999).

Treatment of the hydrocephalus associated with fourth ventricular obstruction by the tumor mass is usually best performed using an external ventriculostomy catheter, which may be inserted at the time of the initial diagnosis if increased intracranial pressure is identified by marked ventricular enlargement on a scan with or without neurologic findings. In most children, the drainage catheter may be placed at the time of the resection. Despite the achievement of a total or near-total tumor resection in most children, as many as $50 \%$ will require a permanent ventricular shunt following the primary procedure, owing to scarring of the CSF pathways and failure of fluid absorption. The likelihood of permanent shunting is increased in those children with leptomeningeal dissemination and in infants, whose absorptive pathways are less fully developed.

Common postoperative findings in these children include diplopia and sixth-nerve palsies secondary to brainstem dissection, which will either resolve spontaneously over several months or require ophthalmologic surgical correction. Ataxia from the vermian dissection and/or upper extremity incoordination from dissection of the cerebellar peduncles may require physical and occupational therapy and almost always improves with time. A previously rarely reported but now more commonly identified postoperative finding is that of mutism-associated pseudobulbar signs, including gait apraxia and flattening of affect appearing 1-3 days after tumor resection. This syndrome has been identified in $5-15 \%$ of children who undergo resection of a large midline posterior fossa tumor irrespective of the pathologic type and is most likely observed in recent patient series because the more aggressive surgical resections are now undertaken with the use of better resolution scans and operative microscopy. The pathologic substrate for the syndrome has not been fully identified, although dissection of the dendate nuclei of the cerebellum has been implicated. Fortunately, complete or near-complete resolution of the neurologic findings has been reported in virtually all cases (Pollack et al., 1995).

\section{Radiation Therapy}

Radiation therapy remains the single most effective means of postoperative treatment for children with medulloblastomas. It is commonly accepted that medulloblastoma is rarely a purely localized disease, even in patients with normal MRIs of the spine and negative CSF cytologies at diagnosis, and that some form of treatment aimed to the entire craniospinal axis is required for disease control. The most significant improvement in survival for children with medulloblastoma occurred when radiation was routinely given to the entire craniospinal axis in newly diagnosed patients, independent of evaluation of extent of disease at the time of diagnosis.

The doses of radiation therapy required for primary site and in neuraxis control for children with medulloblastoma have never been determined by prospective randomized studies. Conventionally, in patients $>3$ years of age, 3600 cGy of craniospinal irradiation has been given to the entire neuraxis, and the posterior fossa receives a total dose of 5400-5960 cGy. There is evidence to suggest that those patients who receive $<4500 \mathrm{cGy}$ to the local tumor site have a higher rate of disease relapse (Hershatter et al., 1982; Landberg et al., 1980).

Because of the potential long-term sequelae of radiation therapy, there have been attempts to decrease the amount of craniospinal irradiation given. Such studies have been performed in children without disseminated disease at the time of diagnosis (Table 2). In one trial performed by the CCG and the Pediatric Oncology Group, children between three and 21 years of age with nondisseminated medulloblastoma were prospectively randomized to receive treatment with either 2340 or 3600 cGy of craniospinal irradiation (Deutsch et al., 1996). In this protocol, patients received the same local dose of radiation therapy and no chemotherapy was utilized. The study was halted when an interim analysis disclosed a higher relapse rate and a higher rate of relapse outside the primary site in children who received the reduced dose of craniospinal irradiation. With longer follow-up, the difference in progression-free survival and overall survival between the two groups narrowed, and at six-year follow-up, the difference in overall survival between the two treatment arms was significant at the 0.058 level (Thomas et al., 1995).

A prospective study performed by the International Society of Pediatric Oncology also attempted to evaluate the efficacy of reduced-dose craniospinal irradiation (Bailey et al., 1995). Children with nondisseminated medulloblastomas were randomized to one of four study arms, including two arms in which patients received preradiation chemotherapy. In the Society's study, there was no 
Table 2. Selected randomized trials for children with newly diagnosed medulloblastomas

\begin{tabular}{|c|c|c|c|}
\hline Trial & Eligibility & Treatment & Primary findings \\
\hline $\begin{array}{l}\text { Evans et al., } 1990 \\
\text { CCG }\end{array}$ & All children & $\begin{array}{l}\text { RT alone or RT plus CCNU, } \\
\text { VCR, prednisone }\end{array}$ & $\begin{array}{l}\text { Staging important; chemotherapy } \\
\text { benefited poor risk }\end{array}$ \\
\hline $\begin{array}{l}\text { Tait et al., } 1990 \\
\text { SIOP }\end{array}$ & All children & RT alone or RT plus CCNU, VCR & Chemotherapy benefited poor risk \\
\hline $\begin{array}{l}\text { Bailey et al., } 1996 \\
\text { SIOP }\end{array}$ & All children $>3$ years & $\begin{array}{l}\text { Pre-RT chemo or post-RT chemotherapy; } \\
\text { full versus reduced dose CSRT; } 6 \text { arms }\end{array}$ & $\begin{array}{l}\text { No benefit pre-RT chemotherapy; reduced } \\
\text { and conventional CSRT equal; poorer } \\
\text { survival if pre-RT chemo and reduced CSRT }\end{array}$ \\
\hline $\begin{array}{l}\text { Deutsch et al., } 1996 \\
\text { CCG/POG }\end{array}$ & Average risk $>3$ years & Reduced or conventional CSRT & $\begin{array}{l}\text { ? Poorer survival and higher non-primary } \\
\text { site relapse if reduced CSRT }\end{array}$ \\
\hline $\begin{array}{l}\text { Zeltzer et al., } 1996 \\
\text { CCG }\end{array}$ & Poor risk >18 months & $\begin{array}{l}\mathrm{RT}+\mathrm{CCNU}, \mathrm{VCR} \text { or RT + pre- and } \\
\text { post-RT 8-in-1 }\end{array}$ & $\begin{array}{l}\text { Staging important; Total or near-total } \\
\text { resection of benefit in nondisseminated; } \\
\text { pre-RT 8-in-1 poorer outcome }\end{array}$ \\
\hline $\begin{array}{l}\text { Kühl et al., } 1998 \\
\text { Germany Cooperative }\end{array}$ & Poor risk $>3$ years & $\begin{array}{l}\text { Aggressive pre-RT chemo vs RT plus } \\
\text { CCNU, VCR, CPDD }\end{array}$ & $\begin{array}{l}\text { Poorer survival if aggressive pre-RT } \\
\text { chemo in nondisseminated }\end{array}$ \\
\hline
\end{tabular}

RT, radiation therapy; CCNU, 1-(2-chloroethyl)-3-cyclohexyl-1-nitrosourea; VCR, vincristine; CPDD, cisplatinum; CCG, Children's Cancer Group; SIOP, International Society of Pediatric Oncology; CSRT, craniospinal radiation therapy; POG, Pediatric Oncology Group.

statistical difference between those patients with nondisseminated medulloblastoma who received reduced-dose craniospinal irradiation therapy as compared with those receiving conventional doses of craniospinal irradiation therapy, as long as radiation therapy was given immediately after surgery. The only subset of children in this study who had a poorer survival rate were those who received preradiation chemotherapy followed by reduced-dose craniospinal radiation. It was postulated that this arm of the study fared less well because of the use of an ineffective preradiation chemotherapy regimen.

In the studies that have used radiation alone, the best five-year disease-free survival rates that have been reported have ranged between 60 and $70 \%$. As noted in the section of this review discussing chemotherapy, there have been attempts to add chemotherapy so as to reduce doses of craniospinal irradiation required for long-term disease control.

Another approach that has been fairly extensively studied has been the use of chemotherapy prior to radiation (Bailey et al., 1995; Kovnar et al., 1990; Zelter et al., 1995). To date, such approaches have not shown clear-cut benefit for children with medulloblastomas and may result in poorer overall disease control (Zelter et al., 1995).

Although most studies have focused on alterations in dose of craniospinal irradiation, especially whole-brain irradiation, in attempts to reduce sequelae, the long-term effects of posterior fossa irradiation are poorly characterized. It is unclear whether posterior fossa irradiation has long-term cognitive impact, and it certainly affects other important structures such as the cochlea with risks of late hearing impairment. New conformal techniques are now being employed that may lessen some of these long-term detrimental effects.

For younger children, especially children less than three years of age at the time of diagnosis, multiple attempts have been made to use chemotherapy as the first treatment after surgery and then to use radiation therapy only when the child is older (Baram et al., 1987; Duffner et al., 1993). In those patients with complete response to chemotherapy, some have elected not to use radiation therapy at all. Since only a minority of children treated with chemotherapy alone have survived (20 to $30 \%$ ), there is increasing interest in introducing radiation therapy earlier in the treatment of infants with medulloblastoma. However, how to best integrate radiation therapy into treatment trials remains unsettled. Focused, or localized, radiation therapy is now being integrated into infant medulloblastoma trials for those patients with localized disease at the time of diagnosis. The use of craniospinal irradiation continues to be extremely problematic for infants with disseminated disease at the time of diagnosis, but a reduced-dose (? 1800 cGy or ? 2400 cGy) is being contemplated in trials that are presently being developed. Craniospinal hyperfractionated radiotherapy has been used in attempts to both increase the efficacy of and reduce the sequelae of craniospinal radiotherapy, but to date, it has not shown a clear-cut advantage over standard fractionated irradiation (Allen et al., 1996; Prados et al., 1994).

\section{Chemotherapy}

\section{Recurrent Disease}

Medulloblastoma is a relatively chemosensitive tumor. Multiple drugs have shown some degree of efficacy in patients with recurrent disease. Since until recently few cell lines of medulloblastoma existed, in vitro evaluation of the potential utility of chemotherapeutic agents was limited. Cell lines now exist for medulloblastoma and have demonstrated that the tumor in culture is sensitive to a variety of agents, especially alkylators such as cyclophosphamide (Packer et al., 1990).

Single-agent drug trials have demonstrated the activity of various drugs including methotrexate, high-dose cyclophosphamide, cisplatinum, and carboplatinum in children with recurrent medulloblastoma (Allen et al., 1987; Ashley et al., 1996; Packer, 1990). As a single agent, high-dose cyclophosphamide was demonstrated to result in objective tumor shrinkage in eight of eight patients with recurrent disease (Allen and Helson, 1981). Cisplatinum, as a single agent, resulted in objective tumor response in nearly $75 \%$ of patients (Sexauer et al., 
1985). Because of the known ototoxicity of cisplatinum, which may be potentiated by prior radiation, other platinum derivatives, especially carboplatinum, have been evaluated in children with medulloblastoma. Carboplatinum, delivered at a dose of approximately 500 to 600 $\mathrm{mg} / \mathrm{m}^{2}$ every three to four weeks, has demonstrated a somewhat disappointing response rate. In one study of children with recurrent medulloblastoma, 6 of 14 patients responded, and in another study, 1 of 15 had an objective response to treatment (Friedman et al., 1992; Gaynon et al., 1990). Some of these patients had been pretreated with cisplatinum, and there is some suggestion that those patients who received prior cisplatinum are less likely to respond to carboplatinum.

More recently, combination chemotherapy has been used in children with recurrent medulloblastoma. The combination of CCNU, vincristine, and cisplatinum resulted in objective tumor shrinkage in six of six patients (Packer, 1988). The 8-drug-in-1-day approach was effective in six of nine patients with medulloblastomas (Pendergrass et al., 1987). The combination of ifosphamide, carboplatinum, and etoposide has also showed a relatively high response rate (Packer, 1990). Although recurrent medulloblastomas have been shown to respond to single agents or combinations of agents, long-term disease control is uncommon after treatment with conventional chemotherapy (Packer, 1990). For this reason, higher-dose multidrug chemotherapy regimens supported by either autologous bone marrow rescue or peripheral stem cell rescue have been used in children with recurrent disease. A variety of different regimens have been employed, and most result in a high response rate. The combination of high-dose thiotepa, etoposide, and carboplatinum was used in 23 patients with recurrent medulloblastoma (Finlay et al., 1996). Seven of 23 remained alive and free of disease a median of 54 months post high-dose chemotherapy; some long-term survivors also were treated with local irradiation. The overall event-free survival in this series of children with recurrent medulloblastoma was $24 \pm 10 \%$. Other high-dose chemotherapy regimens have been employed, but none have demonstrated as high an overall long-term disease control rate (Graham et al., 1997).

\section{Newly Diagnosed Patients}

Based on these somewhat encouraging results in children with recurrent disease, adjuvant chemotherapy trials have been undertaken in children with newly diagnosed medulloblastoma. The initial two prospective trials were performed independently in the late 1970s and early 1980s by the CCG and the International Society of Pediatric Oncology (Evans et al., 1990; Tait et al., 1990). In both studies, newly diagnosed children with medulloblastoma were randomized to receive either radiation therapy alone (3600 cGy of craniospinal irradiation plus a boost to a total dose of between 5400 and 5600 cGy to the tumor site) or identical radiation therapy plus vincristine during radiation therapy and eight cycles of vincristine and CCNU after radiation. For the children on the CCG trial, the postradiation chemotherapy arm also included prednisone. Both of these trials demonstrated statistical benefit for the addition of chemotherapy for children with poor risk medulloblastoma. In the CCG trial, the estimated five-year, progression-free survival was 59\% for children treated with irradiation and chemotherapy and was $50 \%$ for those treated with irradiation alone. In patients with larger bulk tumor at the time of initial surgery and in those with the most extensive tumor, however, there was a demonstrable benefit from the addition of chemotherapy; the event-free survival was $48 \%$ for those receiving chemotherapy as compared with $0 \%$ for those treated with irradiation alone.

Other prospective randomized trials have also suggested a significant benefit for the addition of chemotherapy after radiation therapy. McIntosh and colleagues reported that $81 \%$ of 21 children treated with postradiation therapy, cyclophosphamide, and vincristine were free of disease a median of six years after diagnosis (McIntosh et al., 1985). In the largest single-arm study reported to date, Packer and coworkers treated 63 children with medulloblastoma at four different medical centers using vincristine during radiation therapy and eight cycles of CCNU, vincristine, and cisplatinum after radiation therapy (Packer et al., 1994). Using the same criteria as those in the prospective CCG and International Society of Pediatric Oncology Group studies, children entered on this study were determined to have poor-risk disease. However, only 15 of the 63 had disseminated disease at the time of diagnosis. Progression-free survival for the entire group, at five years, was $85 \pm 6 \%$. Patients with metastatic disease at the time of diagnosis had a five-year progression-free survival rate of $67 \pm 15 \%$ as compared with $90 \pm 6 \%$ for those patients with localized disease at the time of diagnosis.

\section{Preirradiation Chemotherapy}

Another approach for patients with poor-risk medulloblastoma has been to use chemotherapy prior to radiation in attempts to overcome radiation-induced microvascular changes that may be present if chemotherapy is given postradiation, theoretically limiting drug delivery. The largest randomized trial using preirradiation chemotherapy was recently completed by the CCG (Zelter et al., 1995). In this study, children were randomized to receive either treatment with craniospinal and local boost radiotherapy and adjuvant CCNU and vincristine chemotherapy during and after radiation therapy or treatment with the 8-drug-in-1-day approach for two cycles prior to irradiation and then for eight cycles after radiation therapy. This study entered only those patients who were thought to have poor risk disease and demonstrated an overall four-year survival rate of $60 \%$. However, those children who received preradiation chemotherapy fared less well than those patients who were treated with immediate postsurgical radiation therapy and chemotherapy during and after radiation. In a study performed by the International Society of Pediatric Oncology, children with medulloblastoma were randomized to receive either immediate radiation therapy or chemotherapy with vincristine, procarbazine, and methotrexate given in a six-week module before radiation therapy. No benefit for receipt of preradiation chemotherapy could be demonstrated for any risk group 
of children in this study (Bailey et al., 1995). In addition, those children who were treated with preradiation chemotherapy and reduced-dose radiation therapy had a statistically poorer outcome.

Some of the studies that have used preradiation chemotherapy have been criticized because the chemotherapeutic regimens were relatively unaggressive or the individual drugs were given at suboptimal doses. The Germany cooperative group used a more aggressive preradiation chemotherapy approach that included procarbazine, ifosphamide, VP16, methotrexate, cisplatinum, and cytosine arabinoside (Kuhl et al., 1998). Sixty-nine patients in this series had residual tumor or a solid CNS metastasis at the time of treatment, and an objective response rate was observed in $67 \%$ of patients. Overall five-year progression-free survival in this series was $49 \pm$ $5 \%$ in patients with medulloblastoma, and those patients with disseminated disease had a statistically worse survival rate than those with localized disease despite treatment with high-dose chemotherapy. In a recent randomized trial, this intensive regimen has also been compared with vincristine and cisplatinum given after radiation therapy. Children in this trial with nondisseminated medulloblastoma had a poorer overall survival rate if preradiation chemotherapy was employed $(86 \pm 6 \%$ versus $55 \pm 9 \%) .5$ A difference between the two arms for children with metastatic disease could not be demonstrated.

The CCG recently completed a 4-drug combination study using cyclophosphamide, vincristine, VP16, and cisplatinum alternating with carboplatin and VP16 for five cycles prior to the initiation of radiation therapy in children with poor risk medulloblastoma. The results from this study are still being analyzed, but preliminary results suggest there may be difficulties with this approach because nearly $40 \%$ of patients had to begin radiation therapy earlier than planned due to either excessive toxicity or treatment failure. ${ }^{6}$

Although the utility of preradiation chemotherapy for children with medulloblastomas is still open to debate, there is still no clear-cut evidence that such therapy improves survival for children with poor risk medulloblastoma. In addition, there is a growing body of evidence that suggests that for those patients with localized disease, the delay in radiation therapy may result in poorer survival.

\section{Average Risk Disease}

Another potential use of chemotherapy for children with medulloblastoma has been in the treatment of patients with average risk disease, in attempts to both improve survival and possibly allow a reduction in the dose of radiation therapy. The CCG has recently completed a study of reduced-dose craniospinal radiation therapy (2340 cGy) and conventional local doses of radiotherapy (5500 cGy) coupled with adjuvant CCNU, vincristine, and cisplatinum chemotherapy (Packer et al., 1996). Over a three-year period, 65 children between 3 and 10 years of age with nondisseminated medulloblastoma were treated with this approach, resulting in progressionfree survival at three years of $85 \pm 5 \%$ and at five years of $79 \pm 6 \%$. These overall survival rates compare favorably with those from studies where full-dose radiation therapy was given alone, or from other studies where a conventional dose of radiation therapy plus chemotherapy was given. A pilot study using $1800 \mathrm{cGy}$ of craniospinal radiotherapy and the same chemotherapy resulted in long-term disease control in 7 of 10 children, suggesting that it might be possible to even further reduce the dose of craniospinal irradiation in some patients with nondisseminated medulloblastomas (Goldwein et al., 1996).

\section{Infant Studies}

For very young children with medulloblastoma, especially those $<3$ years of age at the time of diagnosis, chemotherapy has been employed in attempts to delay, if not obviate, the need for radiation therapy. The initial study suggesting that this approach may be effective was performed by van Eyes and coworkers at M.D. Anderson Cancer Center and demonstrated long-term survival in 5 of 12 children with medulloblastoma after treatment with mechlorethamine, vincristine, procarbazine, and prednisone (Baram et al., 1987). In the late 1980s, the Pediatric Oncology Group completed a study of the 4drug regimen of cisplatinum, cyclophosphamide, vincristine, and VP16 to treat medulloblastoma. All children were to be irradiated at age three or after two years of chemotherapy and treatment resulted in a median time to relapse of nine months and a $34 \%$ progression-free survival at a median of two years from diagnosis (Duffner et al., 1993). Interestingly, patient relapse $>26$ months after diagnosis was infrequent, raising the question over the necessity of irradiation of patients with complete responses. A similar trial was performed with the 8-drugin-1-day approach, but radiation therapy was not mandated at the end of chemotherapy. With this regimen, the median time to progression was six months and only one relapse occurred beyond 21 months of treatment (Geyer et al., 1994). The French Society of Pediatric Oncology treated 35 children with medulloblastoma under age three with high-dose chemotherapy; $77 \%$ of them relapsed a median of 6.3 months from diagnosis (Kalifa et al., 1992). The German Pediatric Oncology Group, using a high-dose chemotherapy regimen that included procarbazine, ifosphamide, VP16, methotrexate, and ara- $\mathrm{C}$, reported a more encouraging survival rate for children with localized disease at the time of diagnosis, as nearly $80 \%$ were alive and free of progression-free disease after treatment with chemotherapy alone; disease control was poorer in children with disseminated disease at the time of diagnosis (Kuhl et al., 1992).

The CCG recently completed a study in which one of two chemotherapeutic regimens were given to children $<3$ years of age with medulloblastoma. Patients received either an intensified cyclophosphamide, vincristine, cisplatinum, and etoposide regimen or a combination chemotherapeutic approach with ifosphamide, carboplatinum, VP16, and vincristine. In those patients with disease control after induction, maintenance chemotherapy was given for approximately one year. Although the cyclophosphamide- and cisplatinum-containing arm seemed to result in better initial disease control, there was no clear-cut difference in progression-free survival between the two arms (Packer et al., 1998). In this study, 
radiation therapy was not routinely employed unless there was evidence of residual or recurrent disease after treatment with chemotherapy. Even in those patients who did not have demonstrable residual disease prior to the initiation of chemotherapy or those who had a complete response to induction chemotherapy, long-term disease control was disappointing. Progression-free survival fell by nearly $50 \%$ during maintenance chemotherapy.

An even more aggressive chemotherapy approach was attempted by Mason and colleagues for children $<5$ years of age, wherein induction chemotherapy with cyclophosphamide, vincristine, cisplatinum, and VP16 was given, followed by high-dose chemotherapy with thiotepa, carboplatin, and etoposide for those patients who had no evidence of residual disease (Mason et al., 1998). Two-year, progression-free survival for children in this study was $38 \%$, which was not dramatically different from studies utilizing less aggressive chemotherapeutic approaches.

\section{Summary of Chemotherapy}

In summary, in studies completed to date, although chemotherapy can result in long-term disease control in a subset of infants and young children with medulloblastoma, most patients will not be cured after treatment with chemotherapy alone. An alternative approach to the use of chemotherapy alone in infants and young children with medulloblastoma is to use chemotherapy supplemented with some form of radiation therapy early in the course of disease. Dupuis-Girod and colleagues demonstrated that some children who experience disease recurrence after high-dose chemotherapy can be effectively treated with high-dose chemotherapy supported by autologous bonemarrow rescue and localized radiation therapy (DupiusGirod et al., 1996). Patients who seemed to benefit from this approach, however, were those who developed failure only at the primary tumor site.

\section{Long-Term Sequelae of Treatment}

The long-term sequelae of treatment of children with medulloblastoma has been well documented. Although a variety of factors play a role in the development of such sequelae-including pre-operative neurologic status, presence of hydrocephalus at diagnosis, operative and postoperative complications-craniospinal irradiation has been demonstrated as a major cause of such impairments (Packer et al., 1989).

Results of retrospective and prospective studies, although often having serious methodological flaws, have demonstrated that children receiving craniospinal irradiation therapy are at significant risk for progressive intellectual deterioration. This deterioration may not be fully evident until two to three years after diagnosis. The decline in overall intelligence has been most dramatically demonstrated in younger children and especially those $<7$ years of age at the time of treatment. After 3600 cGy of radiation therapy, children $<7$ years of age at the time of diagnosis have declines in overall intelligence of between 20 and 30 points within three years of the completion of radiation therapy. After treatment with lower doses of craniospinal irradiation therapy, in the 2400 cGy range, the decline in overall intelligence seems to be less marked, ranging from between 10 and 20 points (Mulhern et al., 1998). In older children, declines in intelligence are more variable, with some children demonstrating relatively stable overall intelligence (Mulhern et al., 1998; Packer et al., 1989, Radcliffe et al., 1992).

It is clear, however, that intelligence quotients are relatively crude measures of the impact of cranial irradiation on intellectual function (Johnson et al., 1994; Packer et al., 1989). In general, overall scores of performance and verbal intelligence have mirrored results of full-scale intelligence evaluations. Children who have been treated with craniospinal irradiation, however, have shown a wide range of dysfunction on selective functional tests. These have included mild to severe deficits in fine motor skills (which may be related to the tumor or its surgery rather than to radiation), visual motor deficits, visual spatial impairments, and a trend for increasing memory deficits over time. Even in children with relatively wellmaintained overall intelligence, school difficulties are extremely common. It is also increasingly clear that longterm survivors of medulloblastoma may have difficulties in organization and attention, and such "executive" function disabilities will greatly impair learning. Most children $<7$ years of age with medulloblastoma who are treated with surgery and radiation will require special education placement, and a significant number of older children will also need some type of classroom help.

The psychosocial difficulties of children with medulloblastoma have been poorly studied; however, many long-term survivors are at high risk for psychological difficulties as they enter their teenage and adult years (Johnson et al., 1994). They often feel ostracized from their peers because they may differ in appearance (being shorter, having thinner hair, and being overweight), and they have more trouble functioning in and out of school. As these children enter adulthood, many have difficulties in obtaining employment, obtaining insurance, and entering stable long-term relationships.

Endocrinologic sequelae are also well recognized in children surviving medulloblastoma. Due to the cranial irradiation given, prepubertal children are at high-risk for growth hormone deficiency. This, coupled with decreases in skeletal (primarily vertebral) growth due to radiation to the spine and the tendency of children to enter puberty early because of the radiation received, puts these children at high risk for significant linear growth retardation (Olshan et al., 1992; Shalet et al., 1977, 1987; Silber et al., 1990). There is great variability in the use of growth hormone for children surviving medulloblastoma. There has been reluctance to begin growth hormone early after treatment because of the concern that the hormone may result in a higher likelihood of tumor recurrence. However, studies have not demonstrated a higher likelihood of tumor recurrence in children treated with growth hormone after successful brain tumor treatment as compared with patients who were not treated with growth hormone replacement (Shalet et al., 1987).

Other endocrinologic deficits may occur in children surviving medulloblastomas. Thyroid function also occurs relatively commonly and may be due either to hypothalamic 
radiation or to scattered irradiation received by the thyroid gland during craniospinal irradiation (Oberfield et al., 1986). Sexual hormone dysfunction may also occur and may be manifest by precocious puberty or delayed development. Adrenocortical dysfunction, although possible, occurs the least frequently of all hormonal deficits.

As stated previously, cranial irradiation has been identified as the major reason for endocrinologic dysfunction. Most studies have focused on the dose of whole-brain irradiation given in treatment as regards sequelae, but the local tumor portal may also include a portion of the hypothalamus. With new radiation techniques, the hypothalamic and pituitary regions can often be shielded from the local radiation therapy boost. For growth hormone, there is a dose-sequelae relationship, as growth hormone deficiency is more common if doses $>2500 \mathrm{cGy}$ are delivered to the hypothalamus (Shalet et al., 1977, 1987).

These significant endocrinologic, neurocognitive, and psychological sequelae have been major reasons for studies that have attempted to reduce the dose of craniospinal irradiation for children with medulloblastomas. The impact of local radiation therapy, however, has not been well studied. In addition, the long-term effects of highdose chemotherapy on the developing nervous system have just begun to be evaluated.

\section{Synthesis and Future Directions}

Based primarily on prospective clinical studies performed over the past two decades, children with medulloblastoma are usually conceptualized as three relatively distinct patient populations: average risk patients, poor risk patients, and infants. Separation is primarily based upon age, tumor location (if nonposterior fossa tumors are included in studies), neuroradiographic findings, and to a lesser extent, impressions of the surgeon at the time of initial surgery. These separations remain relatively crude, and studies would suggest that an intermediate group of patients with medulloblastoma exists; however, the subgroup between average and poor risk remains difficult to define. There is a clear lack of biologic parameters to supplement clinical prognostic factors, and until those biologic markers become available, stratification of patients into risk groups remains relatively arbitrary.

For children with average risk disease, there seems to be a relative consensus that treatment approaches should employ both radiation therapy and chemotherapy. In 1996, a study was begun by the CCG and the Pediatric Oncology Group that essentially accepted 2400 cGy as the standard craniospinal dose for children with nondisseminated medulloblastoma. In this study, all children with average risk disease are being treated with 2400 cGy of craniospinal irradiation immediately after surgery, 5500 cGy of local radiation therapy, and one of two chemotherapeutic regimens. All patients are receiving vincristine on a weekly basis during radiation therapy and eight cycles of postradiation chemotherapy that includes CCNU, vincristine, and cisplatinum, or CCNU, vincristine, and cyclophosphamide. It is conceivable that after this generation of studies at $2400 \mathrm{cGy}$ of craniospinal irradiation therapy are completed, future studies will focus on reduc- ing even further the dose of craniospinal irradiation in patients with nondisseminated medulloblastoma or reducing the dose of craniospinal radiation therapy and adding intrathecal therapy. Since preradiation chemotherapy has never been clearly demonstrated to improve survival for children with medulloblastomas, and overall survival rates for patients receiving radiation plus chemotherapy are relatively high, preradiation chemotherapy has not been used in this subset of patients.

For children with poor risk medulloblastomas, primarily those with disseminated disease at the time of diagnosis, there is no clear-cut consensus over the best direction for therapy. Preradiation chemotherapy trials are still being performed, primarily with high-dose multiagent chemotherapy. Because radiation therapy still remains the backbone of treatment of children with medulloblastoma, other studies underway are attempting to enhance the efficacy of radiation therapy with chemotherapy given during radiation therapy to act as both an antineoplastic agent and as a radiosensitizer. Another approach soon to be studied is high-dose chemotherapy with peripheral stem cell rescue after craniospinal and local boost radiation therapy.

For infants and young children, there continues to be the hope that radiation can be delayed, if not obviated. Although a subset of children seem to be treated effectively by radiation therapy alone, intensification of treatment has not, as yet, been demonstrated to clearly enlarge this subset. In addition, the age at which physicians are willing to introduce craniospinal radiation therapy varies, and studies that have used chemotherapy as initial (? only) treatment for children with medulloblastoma have used various age eligibility criteria. Most have entered only those children 36 months of age or less at diagnosis, while others have allowed children 60 months of age or less to be accrued to the study. Although the primary direction being taken is to intensify chemotherapy, including the use of even higher-dose chemotherapy supplemented by peripheral stem-cell rescue and/or autologous bone marrow rescue, there is also the growing concern that systemic chemotherapy alone will be inadequate treatment for most infants and young children with medulloblastoma. There is increasing reluctance to maintain children on long-duration maintenance chemotherapy protocols, both because of the lack of proven efficacy of such protocols and because of concern over the development of secondary tumors (Duffner et al., 1993). An earlier introduction of focused radiation therapy in those children with nondisseminated medulloblastomas, possibly after intensive preradiation chemotherapy induction, is one approach being actively pursued. Intrathecal chemotherapy, especially with some of the newer drugs or monoclonal antibody approaches, is being postulated as another means to prophylactically treat the craniospinal axis and possibly avoid the use of craniospinal irradiation. However, the distribution of intrathecal or intraventricular drugs after surgery and the ability to effectively deliver therapy to the entire neuraxis in children with CSF shunts makes such treatment problematic.

In those infants with disseminated disease at the time of diagnosis, therapeutic approaches have been of limited success. Although it is hoped that high-dose systemic 
chemotherapy or use of intrathecal approaches may control a subset of children with leptomeningeal disease, craniospinal irradiation (possibly at a lower dose) may still be required.

Finally, it is well recognized that, independent of the success of treatment, a major challenge in the future is to develop treatment protocols that result not only in a high rate of disease control but also in less neurocognitive and psychosocial sequelae. A major challenge in the future is to develop such treatment approaches and to identify better means to help patients with tumor or treatment-related dysfunction.

\section{References}

Allen, J.C., and Epstein, F. (1982) Medulloblastoma and other primary malignant neuroectodermal tumors of the CNS: The effect of patients' age and extent of disease on prognosis. J. Neurosurg. 57, 446-451.

Allen, J.C., and Helson, L. (1981) High-dose cyclophosphamide chemotherapy for recurrent CNS tumors in children. J. Neurosurg. 55, 749-756.

Allen, J.C., Walker, R.W., Luks, E., Jennings, M., Barfoot, S., and Tan, C. (1987) Carboplatin and recurrent childhood brain tumors. J. Clin. Oncol. 5, 459-463.

Allen, J.C., Donahue, B., DaRosso, R., and Nirenberg, A. (1996) Hyperfractionated craniospinal radiotherapy and adjuvant chemotherapy for children with newly diagnosed medulloblastoma and other primitive neuroectodermal tumors. Int. J. Rad. Oncol. Biol. Phys. 36, 1155-1161.

Ashley, D.M., Meier, L., Kerby, T., Zalduondo, F.M., Friedman, H.S., Gajjar, A., Kun, L., Duffner, P.K., Smith, S., and Longee, D. (1996) Response of recurrent medulloblastoma to low-dose oral etoposide. J. Clin. Oncol. 14, 1922-1927.

Bailey, C.C., Gnekow, A., Wellek, S., Jones, M., Round, C., Brown, J., Phillips, A., and Neidhardt, M.K. (1995) Prospective randomised trial of chemotherapy given before radiotherapy in childhood medulloblastoma:International Society of Paediatric Oncology (SIOP) and the (German) Society of Paediatric Oncology (GPO): SIOP II. Med. Pediatr. Oncol. 25, 166-178.

Baram T.Z., van Eys, J., Dowell, R.E., Cangir, A., Pack, B., and Bruner, J.M. (1987) Survival and neurologic outcome of infants with medulloblastoma treated with surgery and MOPP chemotherapy: A preliminary report. Cancer 60, 173-177

Biegel, J.A., Rorke, L.B., Packer, R.J., Sutton, L.N., Schut, L., Bonner, K., and Emanuel, B.S. (1989). Isochromosome $17 q$ in primitive neuroectodermal tumors of the central nervous system. Genes Chromosomes Cancer 1, 139-147, 1989.

Bloom, H.I.J., and Bessell, E.M. (1990) Medulloblastoma in adults: A review of 47 patients treated between 1952 and 1981. Int. J. Radiat. Oncol. Biol. Phys. 18, 763-772.

Bunin, G.R., Kuijten, R.R., Buckley, J.D., Rorke, L.B., and Meadows, A.T. (1993) Relation between maternal diet and subsequent primitive neuroectodermal brain tumors in young children. N. Engl. J. Med. 329, 536-541.

Chambers, E.F., Turski, P.A., Sobel, D., Wara, W., and Newton, T.H. (1981) Radiologic characteristics of primary cerebral neuroblastomas. Radiology 139, 101-104.

Cogen, P.H., Daneshvar, L., Metzger, A.K., Duyk, G., Edwards, M.S.B., and Sheffield, V.C. (1992). Involvement of multiple chromosome 17p loci in medulloblastoma tumorigenesis. Am. J. Hum. Gene. 50, 581-589.

Cogen, P.H., and Donahue, J.D. (1999) Approaches to the posterior fossa in children. In: Sekhar, L.N., and de Oliveira, E. (Eds.), Cranial Microsurgery: Approaches and Techniques. New York: Thieme. pp. 399-404.

Cogen, P.H., and McDonald, J.D. (1996). Tumor suppressor genes and medulloblastoma. J. Neurooncol. 29, 103-112.

Colt, J.S., and Blair, A. (1998) Parental occupational exposures and risk of childhood cancer. Environ. Health Perspect. 106, 909-925.

Davis, D.G., Wilson, D., Schmitz, M., and Markesbery, W.R. (1993) Lipidized medulloblastoma in adults. Hum. Pathol. 24, 990-995.
Deutsch, M., and Reigel, D.H. (1981) Myelography and cytology in the treatment of medulloblastoma. Int. J. Radiat. Oncol. Biol. Phys. 7, 721-725

Deutsch, M., Thomas, P.R., Krischer, J., Boyett, J.M., Albright, L., Aronin, P., Langston, J., Allen, J.C., Packer, R.J., Linggood, R., Mulhern, R., Stanley, P., Stehbens, J.A., Duffner, P., Kun, L., Rorke, L., Cherlow, J., Freidman, H., Finlay, J.L., and Vietti, T. (1996) Results of prospective randomized trial comparing standard dose neuraxis irradiation (3,600 cGy/20) with reduced neuraxis irradiation $(2,340 \mathrm{cGy} / 13)$ in patients with low-stage medulloblastoma: A combined Childrens Cancer Group-Pediatric Oncology Group study. Pediatr. Neurosurg. 24, 167-176.

Duffner, P.K., Horowitz, M.E., Krischer, J.P., Friedman, H.S., Burger, P.C., Cohen, M.E., Sanford, R.A., Mulhern, R.K., James, H.E., Freeman, C.R., Seidel, F.C., and Kun, L. (1993) Postoperative chemotherapy and delayed radiation in children less than three years of age with malignant brain tumors. N. Eng. J. Med. 328, 1725-1731.

Dupuis-Girod, S., Hartmann, O., Benhamou, E., Doz, F., Mechinaud, F., Bouffet, E., Coze, C., and Kalifa, C. (1996) Will high dose chemotherapy followed by autologous bone marrow transplantation supplant cranio-spinal irradiation in young children treated for medulloblastoma? J. Neurooncol. 27, 87-98.

Eibl, R.H., Kleihues, P., Jat, P.S., and Wiestler, O.D. (1994) A model for primitive neuroectodermal tumors in transgenic neural transplants harboring the SV40 large T antigen. Am. J. Pathol. 144, 556-564.

Evans, A.E., Jenkin, R.D., Sposto, R., Ortega, J.A., Wilson, C.B., Wara, W., Ertel, I.J., Kramer, S., Chang, C.H., Leikin, S.L., and Hammond, G.D. (1990) The treatment of medulloblastoma: Results of a prospective randomized trial of radiation therapy with and without CCNU, vincristine, and prednisone. J. Neurosurg. 72, 572-582.

Finlay, J.L., Goldman, S., Wong, M.C., Cairo, M., Garvin, J., August, C., Cohen, B.H., Stanley, P., Zimmerman, R.A., Bostrom, B., Geyer, J.R., Harris, R.E., Sanders, J., Yates, A.J., Boyett, J.M., and Packer, R.J. (1996) Pilot study of high-dose thiotepa and etoposide with autologous bone marrow rescue in children and young adults with recurrent CNS tumors. J. Clin. Oncol. 14, 2495-2503.

Gajjar, A.J., Heideman, R.L., Douglass, E.C., Kun, L.E., Kovnar, E.H., Sanford, R.A., Fairclough, D.L., Ayers, D., and Look, A.T. (1993) Relation of tumorcell ploidy to survival in children with medulloblastoma.J. Clin. Oncol. 11, 2211-2217.

Gaynon, P.S., Ettinger, L.J., Baum, E.S., Siegel, S.E., Krailo, M.D., and Hammond, G.D. (1990) Carboplatin in childhood brain tumors: A Children's Cancer Study Group phase II trial. Cancer 66, 2465-2469.

Geyer, J.R., Zelzer, P.M., Boyett, J.M., Rorke, L.B., Stanley, P., Albright, A.L., Wisoff, J.H., Milstein, J.M., Allen, J.C., Finlay, J.L., Ayers, G., Shurin, S., Stevens, K., and Bleyer, W.A. (1994) Survival of infants with primitive neuroectodermal tumors of malignant ependymomas of the CNS treated with eight-drugs-in-1-day: A report from the Children's Cancer Group. J. Clin. Oncol. 12, 1607-1615.

Goldwein, J.W., Radcliffe, J., Johnson, J., Moshang, T., Packer, R.J., Sutton, L.N., Rorke, L.B., and D'Angio, G.J. (1996) Updated results of a pilot study of low dose craniospinal irradiation plus chemotherapy for children under 
five with cerebellar primitive neuroectodermal tumors (medulloblastoma). Int. J. Rad. Oncol. Biol. Phys. 34, 899-904.

Gould, V.E., Rorke, L.B., Jansson, D.S., Molenaar, W.M., Trojanowski, J.Q., Lee, V.M.-Y., Packer, R.J., and Franke, W.W. (1990a) Primitive neuroectodermal tumors of the central nervous system express neuroendocrine markers and may express all classes of intermediate filaments. Hum. Pathol. 21, 245-252.

Gould, V.E., Jansson, D.S., Molenaar, W.M., Rorke, L.B., Trojanowski, J.Q., Lee, V.M.-Y., Packer, R.J., and Franke, W.W. (1990b) Primitive neuroectodermal tumors of the central nervous system: Patterns of expression of neuroendocrine markers, and all classes of intermediate filament proteins. Lab. Invest. 62, 498-509.

Graham, M.L., Herndon, J.E. 2nd, Casey, J.R., Chaffee, S., Ciocci, G.H., Krisher, J.P., Kurtzberg, J., Laughlin, M.J., Longee, D.C., Olsen, J.F., Paleologus, N., Pennington, C.N., and Friedman, H.S. (1997) High-dose chemotherapy with autologous stem-cell rescue in patients with recurrent and high-risk pediatric brain tumors. J. Clin. Oncol. 15, 1814-1823.

Hershatter, B.W., Halperin, E.C., and Cox, E.B. (1982) Medulloblastoma: The Duke University Medical Center experience. Int. J. Rad. Oncol. Biol. Phys. 12, 1771-1777.

Janss, A.J., Yachnis, A.T., Silber, J.H., Trojanowski, J.Q., Lee, V.M.-Y., Sutton, L.N., Perilongo, G., Rorke, L.B., and Phillips, P.C. (1996) Glial differentiation predicts poor clinical outcome in primitive neuroectodermal brain tumors. Ann. Neurol. 39, 481-489.

Johnson, D.L., McCabe, M.A., Nicholson, H.S., Joseph, A.L., Getson, P.R., Byrne, J., Brasseux, C., Packer, R.J., and Reaman, G. (1994) Quality of long-term survival in young children with medulloblastoma.J. Neurosurg. 80, 1004-1010.

Kalifa, C., Hartmann, O., Demeocq, F., Vassal, G., Couanet, D., TerrierLacombe, M.J., Valteau, D., Brugieres, L., and Lemerle, J. (1992) Highdose busulfan and thiotepa with autologous bone marrow transplantation in childhood malignant brain tumors: A phase II study. Bone Marrow Transplant. 9, 227-233.

Katsetos, C.D., Frankfurter, A., Christakos, S., Mancall, E.L., Viachos, I.N., and Urich, H. (1993) Differential localization of class III, beta-tubulin isotype and calbindin-D28k defines distinct neuronal types in the developing human cerebellar cortex. J. Neuropathol. Exp. Neurol. 52, 655-666.

Kleihues, P., Burger, P.C., and Scheithauer, B.W. (1993) Histological Typing of Tumours of the Central Nervous System. Springer: New York.

Korf, H.-W., Goetz, W., Herken, R., Theuring, F., Gruss, P., and Schachenmayr W. (1990) S-Antigen and rod-opsin immunoreactions in midline brain neoplasms of transgenic mice: Similarities to pineal cell tumors and certain medulloblastomas in man. J. Neuropathol. Exp. Neurol. 49, 424-437.

Korf, H.-W., Korf, B., Schachenmayr, W., Chader, G.J., and Wiggert, B. (1992) Immunocytochemical demonstration of interphotoreceptor retinoid-binding protein in cerebellar medulloblastoma. Acta. Neuropathol. 83, 482-487.

Kovnar, E.H., Kellie, S.J., Horowitz, M.E., Sanford, R.A., Langston, J.W., Mulhern, R.K., Jenkins, J.J., Douglass, E.C., Etcubanas, E.E., Fairclough, D.L., and Kun, L.E. (1990) Preirradiation cisplatin and etoposide in the treatment of high-risk medulloblastoma and other malignant embryonal tumors of the central nervous system: A phase II study. J. Clin. Oncol. 8, 330-336.

Kuhl, J., Gnekow, A., Havers, W., Lampert, F., Spear, M.J., Maab, E., Grat, N., and Bode, U. (1992) Primary chemotherapy after surgery and delayed irradiation in children under three years of age with medulloblastoma: Pilot trial of the German Pediatric Brain Tumor Study Group. Med. Ped. Oncol. 20, 387. (Abstract)

Kuhl, J., Müller, H.L., Berthold, F., Kortmann, R.-D., Deinlein, F., Maab, E., Graf, N., Gnekow, A., Scheurlen, W., Göbel, U., Wolff, J.E.A., Bamberg, M., Kaatsch, P., Kleihues, P., Rating, D., Sörensen, N., and Wiestler, O.D (1998) Preradiation chemotherapy of children and young adults with malignant brain tumors: Results of the German pilot trial HIT '88/' 89 . Klin. Padiatr. 210, 227-233
Landberg, T.G., Lindgren, M.L., Cavallin-Stahl, E.K., Svahn-Tapper, G.O., Sundbarg, G., Garwicz, S., Lagergren, J.A., Gunnesson, V.L., Brun, A.E., and Cronqvist, S.E. (1980) Improvements in the radiotherapy of medulloblastoma, 1946-1975. Cancer 45, 670-678.

Marinesco, G., and Goldstein, M. (1933) Sur une forme anatomique, non encore decrite, de medulloblastome: Medullo-myo-blastome. Ann. Anat. Pathol. 10, 513-525.

Mason, W.P., Grovas, A., Halpern, S., Dunkel, I.J., Garvin, J., Heller, G., Rosenblum, M., Gardner, S., Lyden, D., Sands, S., Puccetti, D., Lindsley, K., Merchant, T.E., O'Malley, B., Bayer, L., Petriccione, M.M., Allen, J., and Finlay, J.L. (1998) Intensive chemotherapy and bone marrow rescue for young children with newly diagnosed malignant brain tumors. J. Clin. Oncol. 16, 210-221.

McDonald, J.D., Daneshvar, L., Willert, J.R., Matsumura, K., Waldman, F., and Cogen, P.H. (1994) Physical mapping of chromosome 17p13.3 in the region of a putative tumor suppressor gene important in medulloblastoma. Genomics 23, 229-232.

Mclntosh, S., Chen, M., Sartain, P.A., Duncan, C., Fishburn, R., Klatskin, E.H., Schwartz, A.D., and Venes, J.L. (1985) Adjuvant chemotherapy for medulloblastoma. Cancer 56, 1316-1319.

Molenaar, W.N., Jansson, D.S., Gould, V.E., Rorke, L.B., Franke, W.W., Lee, V.M.-Y., Packer, R.J., and Trojanowski, J.Q. (1989) Molecular markers of primitive neuroectodermal tumors and other pediatric central nervous system tumors: Monoclonal antibodies to neuronal and glial antigens distinguish subsets of primitive neuroectodermal tumors. Lab. Invest. 61, 635-643.

Molenaar, W.M., Rorke, L.B., and Trojanowski, J.Q. (1994) Neuronal tumors. In: Colvin, R.B., Bhan, A.K., and McCluskey, R.T. (Eds.) Diagnostic Immunopathology. Second edition. New York: Raven Press. pp. 651-668.

Mulhern, R.K., Kepner, J.L., Thomas, P.R., Armstrong, F.D., Friedman, H.S., and Kun, L.E. (1998) Neuropsychologic functioning of survivors of childhood medulloblastoma randomized to receive conventional or reduceddose craniospinal irradiation: A Pediatric Oncology Group study. J. Clin. Oncol. 16, 1723-1728.

Nakagawara, A., Arima-Nakagawara, M., Scavarda, N.J, Azar, C.G., Cantor, A.B., and Brodeur, G.M. (1993) Association between high levels of expression of the TRK gene and favorable outcome in human neuroblastoma. $N$. Engl. J. Med. 328, 847-854.

Oberfield, S.E., Allen, J.C., Pollack, J., New, M.I., and Levine, L.S. (1986) Longterm endocrine sequelae after treatment of medulloblastoma: Prospective study of growth and thyroid function. J. Pediatr. 108, 219-223.

Olshan, J.S., Gubernick, J., Packer, R.J., D'Angio, G.J., Goldwein, J.W., Willi, S.M., and Moshang, T., Jr. (1992) The effects of adjuvant chemotherapy on growth in children with medulloblastoma. Cancer 70, 2013-2017.

Packer, R.J (1990) Chemotherapy for medulloblastoma/primitive neuroectodermal tumors of the posterior fossa. Ann. Neurol. 28, 823-828.

Packer, R.J., Deutsch, M., Thomas, P.R.M., Boyett, J., Kun, L., and Friedman, H. (1996) What constitutes standard therapy for children older than 3 years of age with non-disseminated medulloblastoma. Ann. Neurol. 40, 292-293.

Packer, R.J., Geyer, R., Jennings, M., Boyett, J., Ater, J., Axtell, R., Breiger, D., Donohue, B., Finlay, J., Goldwin, J., Meier, L., Johnson, D., Maczewski, C., Miller, D., Neuberg, R., Pucetti, D., Raffel, C., Radcliffe, J., ShiminskiMaher, T., and Zelter, P. (1998) Disease control in infants and young children with medulloblastomas and ependymomas using chemotherapy alone: A Children's Cancer Group study. Ann. Neurol. 44, 537.

Packer, R.J., Siegel, K.R., Sutton, L.N., Evans, A.E., D'Angio, G., Rorke, L.B., Bunin, G.R., and Schut, L. (1988) Efficacy of adjuvant chemotherapy for patients with poor-risk medulloblastoma: A preliminary report. Ann. Neurol. 24, 503-508.

Packer, R.J., Sutton, L.N., Atkins, T.E., Radcliffe, J., Bunin, G.R., D'Angio, G.J., Siegel, K.R., and Schut, L. (1989) A prospective study of cognitive function in children receiving whole-brain radiotherapy and chemotherapy: 2-Year results. J. Neurosurg. 70, 707-713. 
Packer, R.J., Sutton, L.N., Elterman, R., Lange, B., Goldwein, J., Nicholson, H.S., Mulne, L., Boyett, J., D'Angio, G., Wechsler-Jentzsch, K., Reaman, G., Cohen, B., Bruce, D.A., Rorke, L.B., Malloy, P., Ryan, J., LaFond, D., Evans, E., and Schut, L. (1994) Outcome for children with medulloblastoma treated with radiation and cisplatin, $C C N U$, and vincristine chemotherapy. J. Neurosurg. 81, 690-698.

Packer, R.J., Sutton, L.N., Rorke, L.B., Littman, P.A., Sposto, R., Rosenstock, J.G. Bruce, D.A., and Schut, L. (1984) Prognostic importance of cellular differentiation in medulloblastoma of childhood. J. Neurosurg. 61, 296-301.

Pearl, G.S., and Takei, Y. (1981) Cerebellar "neuroblastoma." Nosology as it relates to medulloblastoma. Cancer 47, 772-779.

Pendergrass, T.W., Milstein, J.M., Geyer, J.R., Mulne, A.F., Kosnik, E.J., Morris, J.D., Heideman, R.L., Ruymann, F.B., Stuntz, J.T., and Bleyer, W.A. (1987) Eight drugs in one day chemotherapy for brain tumors: Experience in 107 children and rationale for preradiation chemotherapy. J. Clin. Oncol. 5, 1221-1231.

Pollack, I.F., Polinko, P., Albright, A.L., Towbin, R., and Fitz, C. (1995) Mutism and pseudobulbar symptoms after resection of posterior fossa tumors in children: Incidence and pathophysiology. Neurosurgery 37, 885-893.

Prados, M.D., Wara, W.M., Edwards, M.S.B., and Cogen, P.H. (1994) Hyperfractionated craniospinal radiation therapy for primitive neuroectodermal tumors: Early results of a pilot study. Int. J. Rad. Oncol. Biol. Phys. 28, 431-438.

Radcliffe, J., Packer, R.J., Atkins, T.E., Bunin, G.R., Schut, L., Goldwein, J.W., and Sutton, L.N. (1992) Three- and four-year cognitive outcome in children with noncortical brain tumors treated with whole-brain radiotherapy. Ann. Neurol. 32, 551-554.

Reardon, D.A., Michalkiewicz, E., Boyett, J.M., Sublett, J.E., Entrekin, R.E., Ragsdale, S.T., Valentine, M.B., Behm, F.G., Li, H., Heideman, R.L., Kun, L.E., Shapiro, D.N., and Look, A.T. (1997) Extensive genomic abnormalities in childhood medulloblastoma by comparative genomic hybridization. Cancer Res. 57, 4042-4047.

Rorke, L.B. (1983) The cerebellar medulloblastoma and its relationship to primitive neuroectodermal tumors. J. Neuropathol. Exp. Neurol. 42, 1-15.

Rorke, L.B. (1994) Introductory survey of brain tumors. In: Cheek, W.R., Marlin, A.E., McLone, D.G., Reigel, D.H., and Walker, M.L. (Eds.), Pediatric Neurosurgery: Surgery of the Developing Nervous System. Third edition. Philadelphia:W.B. Saunders Company, pp. 351-355.

Rorke, L.B., Gilles, F.H., Davis, R.L., and Becker, L.E. (1985) Revision of the World Health Organization classification of brain tumors for childhood brain tumors. Cancer 56 (Suppl. 7), 1869-1886.

Rorke, L.B., Packer, R.J., and Biegel, J.A. (1996) Central nervous system atypical teratoid/rhabdoid tumors of infancy and childhood: Definition of an entity. J. Neurosurg. 85, 56-65.

Rorke, L.B., Trojanowski, J.Q., Lee, V.M.-Y., Zimmerman, R.A., Sutton, L.N. Biegel, J.A., Goldwein, J.W., and Packer, R.J. (1997) Primitive neuroectodermal tumors of the central nervous system. Brain Pathol. 7, 765-784.

Rubinstein, L.J. (1970) The definition of the ependymoblastoma. Arch. Pathol. 90, 35-45.

Sandhu, A., and Kendall, B. (1987) Computed tomography in management of medulloblastomas. Neuroradiology 29, 444-452.

Scheurlen, W.G., Schwabe, G.C., Joos, S., Mollenhauer, J., Sörensen, N., and Kühl, J. (1998) Molecular analysis of childhood primitive neuroectodermal tumors defines markers associated with poor outcome. J. Clin. Oncol. 16, 2478-2485.
Segal, R.A., Goumnerova, L.C., Kwon, Y.K., Stiles, C.D., and Pomeroy, S.L. (1994) Expression of the neurotrophin receptor TrkC is linked to a favorable outcome in medulloblastoma. Proc. Natl. Acad. Sci. U. S. A. 91, 12867-12871.

Sexauer, C.L., Khan, A., Burger, P.C., Krishner, J.P., Van Eyes, J., Vats, T., and Ragab, A.H. (1985) Cisplatin in recurrent pediatric brain tumors: A POG phase II study. Cancer 56, 1497-1501.

Shalet, S.M., Beardwell, C.G., Twomey, J.A., Jones, P.H., and Pearson, D. (1977) Endocrine function following the treatment of acute leukemia in childhood. J. Pediatr. 90, 920-923.

Shalet, S.M., Gibson, B., Swindell, R., and Pearson, D. (1987) Effect of spinal irradiation on growth. Arch. Dis. Child. 62, 461-464.

Silber, J.H., Littman, P.S., and Meadows, A.T. (1990) Stature loss following skeletal irradiation for childhood cancer. J. Clin. Oncol. 8, 304-312.

Soylemezoglu, F., Soffer, D., Onol, B., Schwechheimer, K., and Kleihues, P. (1996) Lipomatous medulloblastoma in adults: A distinct clinicopathological entity. Am. J. Surg. Pathol. 20, 413-418.

Tait, D.M., Thornton-Jones, H., Bloom, H.J., Lemerle, J., and Morris-Jones, P. (1990) Adjuvant chemotherapy for medulloblastoma: The first multi-centre control trial of the International Society of Paediatric Oncology (SIOP I). Eur. J. Cancer 26, 464-469.

Thomas, G.A., and Raffel, C. (1991) Loss of heterozygosity on 6q, 16q, and $17 \mathrm{p}$ in human central nervous system primitive neuroectodermal tumors. Cancer Res. 51, 639-643.

Thomas, P.R., Deutsch, M., Mulhern, R., Stehbens, J., Krishner, J.P., Boyett, J.M., Shuster, J.J., Linggood, R.M., Kun, L., Finlay, J., Friedman, G.D., Packer, R.J., Aronin, P.A., Albright, L.A., Viette, T.J., and Hammond, G.D. (1995) Reduced dose vs standard dose neuraxis irradiation in low stage medulloblastoma: The POG and CCG study. Med. Pediatr. Oncol. 24, 277. (Abstract)

Vezina, L.G., and Packer, R.J. (1994) Infratentorial brain tumors of childhood. Neuroimaging Clin. N. Am. 4, 423-436.

Xie, J., Johnson, R.L., Zhang, X., Bare, J.W., Waldman, F.M., Cogen, P.H., Menon, A.G., Warren, R.S., Chen, L.-C., Scott, M.P., and Epstein, E.H. (1997). Mutations of the PATCHED gene in several types of sporadic extracutaneous tumors. Cancer Res. 57, 2369-2372.

Yagishita, S., Itoh, Y., Chiba, Y., Yamashita, T., Nakazima, F., and Kuwabara, T. (1980) Cerebellar neuroblastoma: A light and ultrastructural study. Acta. Neuropathol. 50, 139-142.

Zahm, S.H., and Ward, M.H. (1998) Pesticides and childhood cancer. Environ. Health Perspect. 106 (Suppl. 3), 893-908.

Zeltzer, P., Boyett, J., Finlay, J.L., Albright, L., Wisoff, J., Geyer, R., McGuire-Cullen, P., Rorke, L.B., Stevens, K., Shurin, S., Milstein, J., and Packer, R.J. (1995) Tumor staging at diagnosis and therapy type for PNET determine survival. Report from the Children's Cancer Group CCG-921. Med. Pediatr. Oncol. 25, 238. (Abstract)

Zerbini, C., Gelber, R.D., Weinberg, D., Sallan, S.E., Barnes, P., Kupsky, W., Scott, R.M., and Tarbell, N.J. (1993) Prognostic factors in medulloblastoma, including DNA ploidy. J. Clin. Oncol. 11, 616-622.

Zimmerman, R.A., Bilaniuk, L.T., and Pahlajani, H. (1978) Spectrum of medulloblastomas demonstrated by computed tomography. Radiology 126 , 137-141.

Zimmerman, R.A., Bilaniuk, L.T., and Rebsamen, S. (1992) Magnetic resonance imaging of pediatric posterior fossa tumors. Pediatr. Neurosurg. 18, 58-64. 